NISTIR 7382

\title{
Effects of Scanner Height on Fingerprint Capture
}

\author{
Mary Theofanos \\ Shahram Orandi \\ Ross Micheals \\ Brian Stanton \\ Nien-Fan Zhang \\ Information Access Division \\ Information Technology Laboratory
}

December 2006

National Institute of Standards and Technology

Technology Administration, U.S. Department of Commerce 


\title{
NISTIR 7382
}

\section{Effects of Scanner Height on Fingerprint Capture}

\author{
Mary Theofanos \\ Ross Micheals \\ Brian Stanton \\ Nien-Fan Zhang \\ U.S. Department of Commerce \\ Technology Administration \\ National Institute of Standards and Technology \\ Information Technology Lab \\ Gaithersburg, MD 20899 \\ Shahram Orandi \\ MitreTek Systems \\ Falls Church, VA
}

December 2006

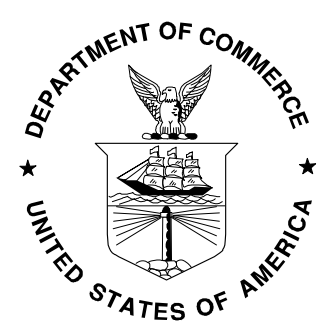

U.S. Department of Commerce Carlos M. Gutierrez, Secretary

Technology Administration Robert Cresanti, Under Secretary of Commerce for Technology

National Institute of Standards and Technology William Jeffrey, Director 


\section{Table of Contents}

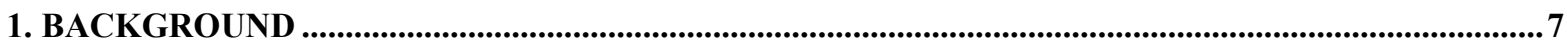

2. INTRODUCTION

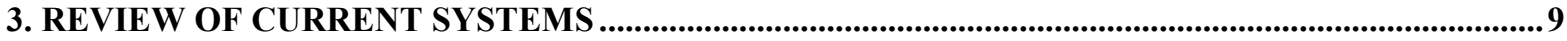

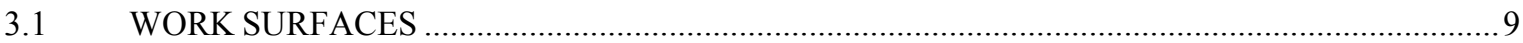

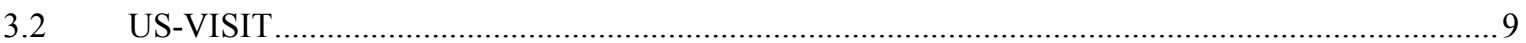

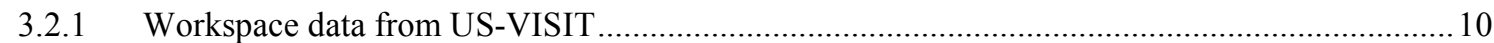

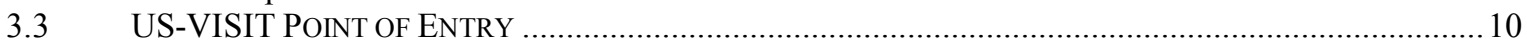

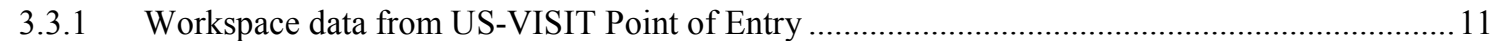

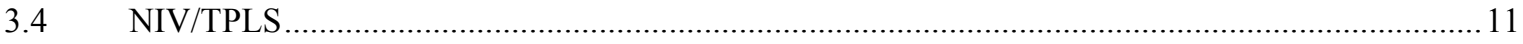

3.4.1 Workspace data from Department of State's NIV system ………............................................... 11

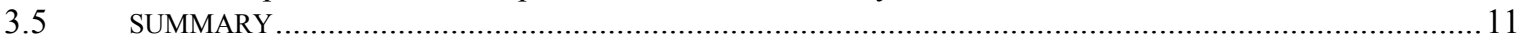

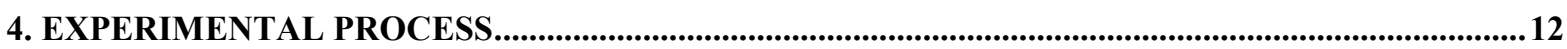

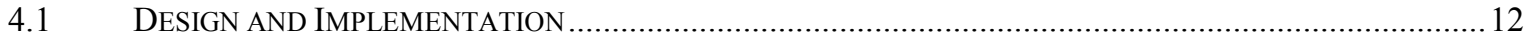

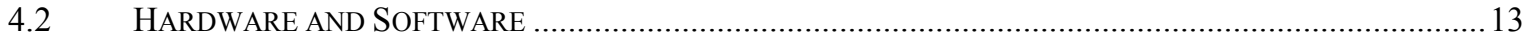

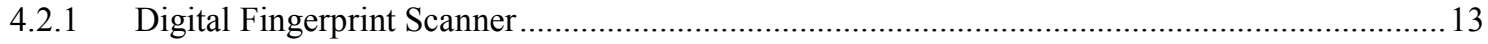

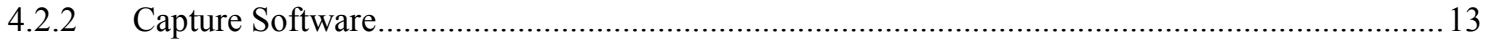

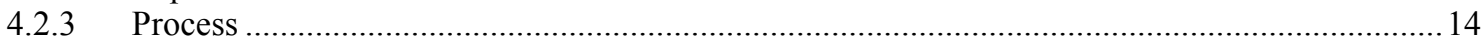

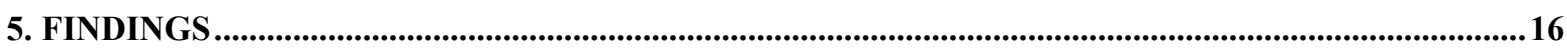

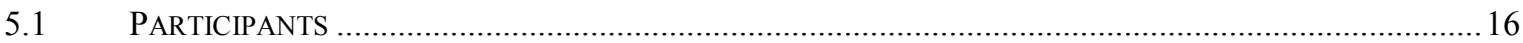

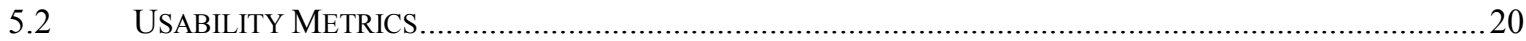

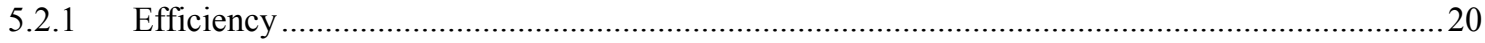

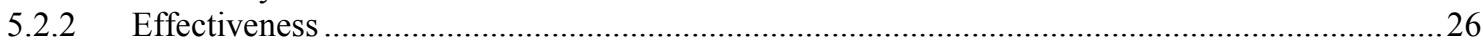

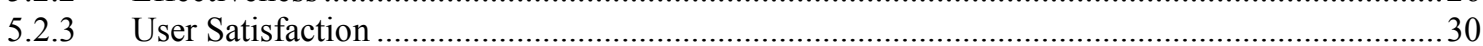

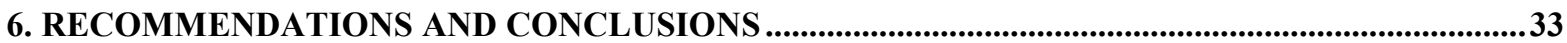

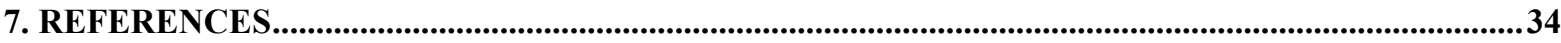

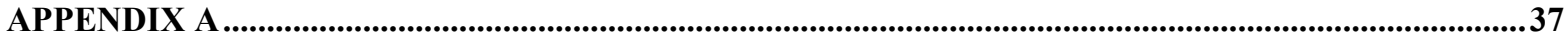

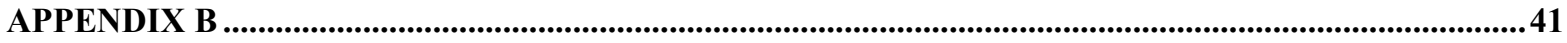

APPENDIX C 


\section{$\underline{\text { List of Figures }}$}

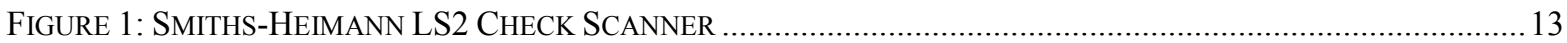

Figure 2: SCANNER TEST APPARATUS SHOWN IN EACH OF THE Four HEIGHT AdJUSTMENTS .......................... 14

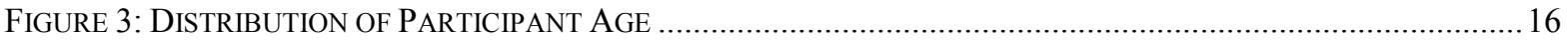

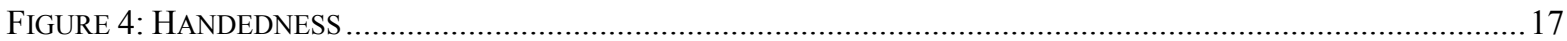

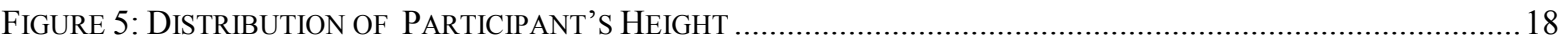

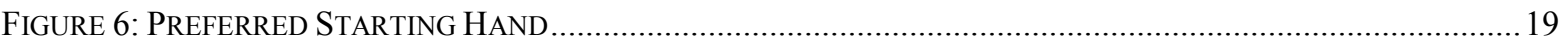

FIGURE 7: HISTOGRAM DEMONSTRATING NON-NORMAL DISTRIBUTION OF DATA (LEFT SLAP TASK EXAMPLE) ....21

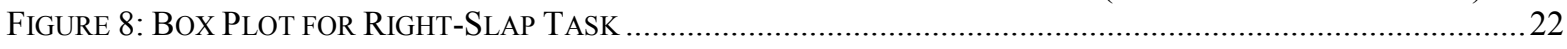

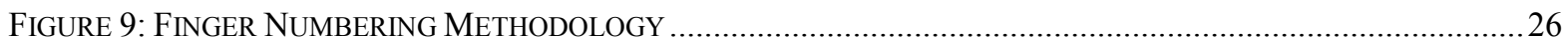

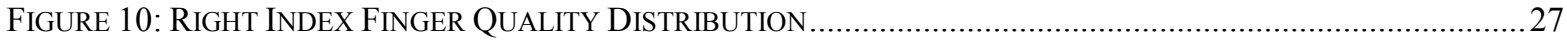

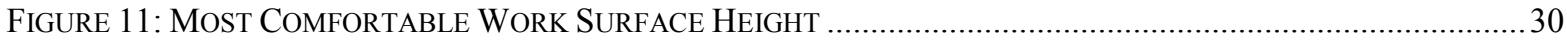

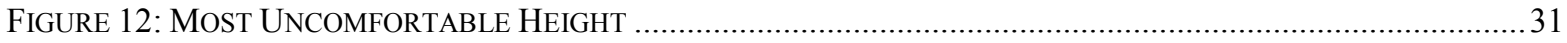

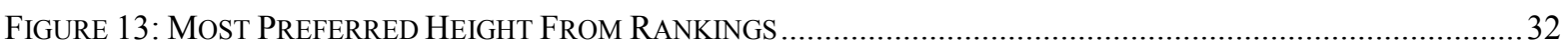

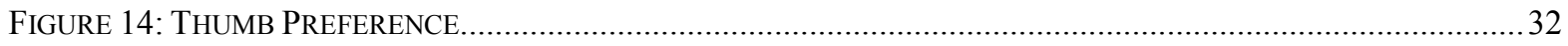




\section{Executive Summary}

Despite the increased deployment of biometric technologies, little attention is being paid to the human factors that such technologies involve. While numerous usability guidelines exist for other systems such as interfaces for desktop computers, no such guidelines have been developed for interacting with biometric hardware and software.

The use of biometric applications will be unfamiliar to many users, who may neither understand nor be comfortable with the technology. Since user behavior can affect both the throughput of the system as well as the quality of the captured images, guidelines for developing interactions with biometric applications that increase throughput and image quality would be valuable to both developers and end-users. Designs that help end users understand and comfortably navigate workflow may reduce the time it takes to obtain images thus improving the process for both the participant and the operator.

This report presents the results of a study that examined the effect of the height of the sensor on the quality and the time required to collect prints ${ }^{1}$. The study was designed to answer three questions:

1. Does work surface height affect the time required to capture fingerprint images?

2. Does work surface height affect the quality of the captured images?

3. Do users prefer a particular work surface height?

Most existing biometric systems are retrofitted into existing infrastructures. A cursory examination of deployed fingerprint systems identified that work surface heights vary greatly (from 32 to 50 inches, $813 \mathrm{~mm}$ to $1270 \mathrm{~mm}$ ) across facilities. The heights used in the study were identified via the Department of Defense and commercial guidelines for surface heights. These guidelines recommend a height of 26.0 inches $(660 \mathrm{~mm})$ for tables, 32.0 inches $(813 \mathrm{~mm})$ for desks, 36.0 inches $(914 \mathrm{~mm})$ for counters, and 42.0 inches $(1067 \mathrm{~mm})$ for stand-up counters. The fingerprint scanner used in the experiment had a height of 6.0 inches $(152 \mathrm{~mm})$.

\footnotetext{
1 These tests were performed for the Department of Homeland Security in accordance with section 303 of the Border Security Act, codified as 8 U.S.C. 1732. Specific hardware and software products identified in this report were used in order to perform the evaluations described in this document. In no case does such identification imply recommendation or endorsement by the National Institute of Standards and Technology, nor does it imply that the products and equipment identified are necessarily the best available for the purpose.
} 
The experimental procedure may be summarized as follows. Seventy-five National Institute of Standards and Technology (NIST) employees participated in the experiment. From each participant we collected five types of fingerprint images:

- A left slap (all fingers on the left hand except for the thumb)

- A right slap (all fingers on the right hand except for the thumb)

- Individual thumb prints (a left thumb or right thumb)

- Simultaneous thumb prints (both thumbs)

The order of presentation of the slaps and the work surface heights were counter-balanced so that every possible combination of slaps appeared at each work surface height. The study population ranged in age from 17 to 67 mirroring the United States Visitor and Immigrant Status Indicator Technology (US-VISIT) population. The population was also representative with respect to U.S. population height based on data from the Centers for Disease Control and Prevention (CDC).

We used the definition of usability in ISO 9241-11, "Ergonomic requirements for office work with visual display terminals (VDTs)," and measured efficiency, effectiveness, and user satisfaction. Efficiency was measured as time on task. Statistical analysis shows that users perform faster at a 36 inch $(914 \mathrm{~mm})$ work surface height. Effectiveness was measured by the NIST Fingerprint Image Quality score (NFIQ). Statistical analysis shows that the image quality was best at the lower surface heights of 26 inch $(660 \mathrm{~mm})$ and 32 inch $(813$ $\mathrm{mm}$ ). Following the collection of the fingerprints for each height, the participants were asked questions to determine which height was most comfortable and which was least comfortable. Users preferred the $32 \mathrm{inch}(813 \mathrm{~mm})$ and 36 inch $(914 \mathrm{~mm})$ heights and were the most uncomfortable at the 42 inch $(1067 \mathrm{~mm})$ height stating that it was difficult, uncomfortable, and awkward to position both thumbs at 42 inches $(1067 \mathrm{~mm})$.

Assuming that all five fingerprint images are collected for a given user, the results can be summarized by the following recommendations for a ten-print capture sequence with a six inch high sensor:

- a counter height of 36 inches $(914 \mathrm{~mm})$ gives the fastest performance

- a counter height of 26 inches $(660 \mathrm{~mm})$ gives the highest quality performance

- a counter height of 32 or 36 inches $(813 \mathrm{~mm}$ or $914 \mathrm{~mm})$ is the most comfortable for users

- starting a capture sequence with the right slap was most efficient

- capturing individual thumb prints yields higher quality images than capturing simultaneous thumb prints

- a counter height of 42 inches $(1067 \mathrm{~mm})$ or higher does not satisfy the efficiency, effectiveness, nor satisfaction requirements. 


\section{BACKGROUND}

Since the release of the 9/11 Commission Report [911COM1], there has been an increased recognition of the importance of the role of national standards in Border and Transportation Security:

Recommendation: The U.S. border security system should be integrated into a larger network of screening points that includes our transportation system and access to vital facilities, such as nuclear reactors. The President should direct the Department of Homeland Security to lead the effort to design a comprehensive screening system, addressing common problems and setting common standards with system wide goals in mind. Extending those standards among other governments could dramatically strengthen America and the world's collective ability to intercept individuals who pose catastrophic threats.

The Commission Report places a particular emphasis on the use of biometrics in border and transportation security:

Recommendation: The Department of Homeland Security, properly supported by the Congress, should complete, as quickly as possible, a biometric entry-exit screening system, including a single system for speeding qualified travelers. It should be integrated with the system that provides benefits to foreigners seeking to stay in the United States. Linking biometric passports to good data systems and decision making is a fundamental goal. No one can hide his or her debt by acquiring a credit card with a slightly different name. Yet today, a terrorist can defeat the link to electronic records by tossing away an old passport and slightly altering the name in the new one.

NIST, which has an established expertise in evaluating biometrics, has been assigned, according to the USA PATRIOT Act (Public Law 107-56) the responsibility of developing and certifying biometric technology standards for verifying the identity of foreign travelers entering and existing the US. NIST has been supporting biometric standards and evaluation activities for over forty years, starting with fingerprint analysis which began in 1965. In the past few years, NIST has had several major open evaluations. These evaluations have traditionally focused on performance and error rates of systems and algorithms.

Although the deployment of biometric technologies such as fingerprints is becoming more widespread, little attention is being paid to the human-computer interaction that such technologies involve. While numerous guidelines exist for the design of user interfaces for 
desktop computers, no such guidelines have been developed for interacting with biometric hardware and software.

The use of biometrics will be unfamiliar to many users, who will not understand the technology, nor be comfortable with using it. Since user behavior can affect both throughput of the system as well as the quality of the captured images, guidelines for developing interactions with biometric applications that increase throughput and image quality would be valuable to the biometrics community. This would help them develop hardware, software, and interaction techniques that would produce good quality biometrics. Designs that help end users understand the biometric hardware and process would reduce the time it takes to obtain images improving the process for both the participant and the operator.

\section{INTRODUCTION}

The quality of captured biometric data is influenced by the human computer interaction and usability. Low quality biometric data may result in a high rate of false matches/mismatches, unpredictable data volume growth in the overall system as well as drops in system process throughput. Biometric data quality can be summarized into the following components [M1/05-0306]:

1) The physical characteristics of a subject that can be used to uniquely identify that subject.

2) The ability to capture the subject's unique characteristics in a usable, repeatable and predictable fashion.

3) The ability for the system to utilize the captured characteristics and establish relevance to other captured data.

Most biometric systems employ both hardware and software measures to maximize the capture quality of the biometric data being presented to the system. Some will actively interact with users on how to improve the capture process. While these measures are effective in minimizing error and maximizing quality for the biometric data presented to the system, the physical presentation of that biometric data by the subject to the system involves many anthropometric and ergonomic factors that have been largely ignored. Not factoring in basic ergonomics and anthropometrics can create situations that can range from having to spend a significant amount of extra time processing a poor quality sample, to the worst case where a subject simply cannot present their biometric sample to the system for an effective 
capture of the biometric data. This study focuses on scanner placement height, and the effect of height on the quality and the time required to collect fingerprints. ${ }^{2}$

\section{REVIEW OF CURRENT SYSTEMS}

\subsection{WORK SURFACES}

Work surfaces are typically designed to standards for work surfaces. The Department of Defense's guidelines for positioning of a work surface recommend 25.5 inches $(648 \mathrm{~mm})$ to 36.0 inches $(914 \mathrm{~mm})^{3}$ from the floor for a seated console and 36.0 inches $(914 \mathrm{~mm})$ for a standing console [M1472]. A supplement to the Department of Defense's original guidelines calls for a work surface to be $36.0 \pm 0.6$ inches $(915 \pm 15 \mathrm{~mm})$ from the floor [M759]. Commercial guidelines include suggested surface heights of 26.0 inches $(660 \mathrm{~mm})$ for tables used in keyboard data entry and typing, 31.0 inches $(787 \mathrm{~mm})$ for tables used for sewing, 36.0 inches $(914 \mathrm{~mm})$ for food service counters and 42.0 inches $(1067 \mathrm{~mm})$ for bank stand-up counters $[\mathrm{AGS}]$. These guidelines are typically based on collected anthropometric data and take into account population usability within the $5^{\text {th }}$ and $95^{\text {th }}$ percentile of all users.

To better understand the range of the work surfaces of the typical biometric system, the team visited several operational systems. This section reviews the visited systems and identifies the configurations for capturing fingerprints.

\subsection{US-VISIT}

United States Visitor and Immigrant Status Indicator Technology (US-VISIT) is a biometrically-enhanced identification system primarily situated at border points of entry such as airports and seaports. US-VISIT processing currently applies to most non-citizens entering the United States, regardless of country of origin and mode of transportation.

2 These tests were performed for the Department of Homeland Security in accordance with section 303 of the Border Security Act, codified as 8 U.S.C. 1732. Specific hardware and software products identified in this report were used in order to perform the evaluations described in this document. In no case does such identification imply recommendation or endorsement by the National Institute of Standards and Technology, nor does it imply that the products and equipment identified are necessarily the best available for the purpose.

${ }^{3}$ Work surface heights of 26 inches, 32 inches, 36 inches and 42 inches are based on common architectural guidelines for tables, desks, counters and standing counters respectively. SI units for these surface heights are presented here for reference, but will not be repeated throughout the remainder of this document. 
Individuals processed by the US-VISIT entry procedures undergo livescan (digital and inkless) fingerprint scans as well as a facial imaging via a conventional webcam. This is an operator assisted capture process with an experienced Customs and Border Protection (CBP) agent guiding each step of processing. If further processing is required, the individual is directed to a US-VISIT secondary processing area.

The US-VISIT exit procedure involves an unmanned kiosk that guides the subject by videos/animation. In the exit procedure, digital fingerprints and photographs are again collected from the subject.

The US-VISIT process is currently based on a two-print capture process, the left and right index fingers of the individual.

\subsubsection{Workspace data from US-VISIT}

The following heights were measured at one US-VISIT location and are provided as a sample.

US-VISIT Primary

Scanner platen height from floor: $\quad 48$ inches $(1219 \mathrm{~mm})$

Scanner counter height from floor: $\quad 46$ inches $(1168 \mathrm{~mm})$

US-VISIT Secondary

Scanner platen height from floor: $\quad 45$ inches $(1143 \mathrm{~mm})$

Scanner counter height from floor: $\quad 43$ inches $(1092 \mathrm{~mm})$

US-VISIT Exit Kiosk

Scanner platen height from floor: $\quad 36$ inches $(914 \mathrm{~mm})$

\subsection{US-VISIT POINT OF ENTRY}

The US-VISIT Point of Entry (POE) is a system that is primarily situated at US Customs and Border Protection Border Patrol stations throughout the country, with an emphasis on placement at land border stations. Individuals processed by the US-VISIT POE procedures undergo either livescan fingerprint scans or inked-fingerprint processing utilizing a document scanner, and a digital photograph is taken of the subject upon entry to the United States. This process is also operator assisted with an experienced Customs and Border Protection agent overseeing each step of processing.

The US-VISIT POE process supports either a two-print or ten-print capture process. 


\subsubsection{Workspace data from US-VISIT Point of Entry}

The following heights were measured at one US-VISIT POE location and are provided as a sample.

Primary workstation (airport configuration, with a 10-print scanner):

Scanner platen height from floor: $\quad 36$ inches $(914 \mathrm{~mm})$

Scanner counter height from floor: $\quad 29$ inches $(737 \mathrm{~mm})$

\subsection{NIV/TPLS}

The Department of State's Non-Immigrant Visa/Ten Print Live Scan (NIV/TPLS) system is situated at every US Department of State (DOS) Consular Office throughout the world that processes visa applications for non-immigrants seeking entry into the US. Individuals processed by the NIV system undergo livescan fingerprinting. This process is operator assisted by an experienced Department of State agent overseeing each step of processing. The NIV process currently supports two-print capture, with a planned upgrade to a ten-print process in the near future.

\subsubsection{Workspace data from Department of State's NIV system}

The following heights were measured at one DOS location and are provided as a sample.

Stand-up counter configuration:

Scanner counter height from floor: 42 inches $(1067 \mathrm{~mm})$

Table configuration:

Scanner counter height from floor: 33 inches $(838 \mathrm{~mm})$

\subsection{SUMMARY}

Not surprisingly, we found that most existing biometric systems are retrofitted into existing physical infrastructures. For example, a biometric enrollment station at a visa processing facility will most likely be deployed at the existing paper enrollment and processing station. Mismatches between the originally intended application versus the current operational application are often a major source of practical facility challenges. For example, a system that utilizes an Identix TP3000 scanner will have its platen located at approximately 6.3 inches $(160 \mathrm{~mm})$ from the counter surface. If a counter surface is situated at 42 inches $(1067 \mathrm{~mm})$ satisfying the $5^{\text {th }}$ to $95^{\text {th }}$ percentile of the population for a standing work surface, 
placing a scanner that is 6.3 inches $(160 \mathrm{~mm})$ high on this surface will raise the operational surface height to 48.3 inches $(1227 \mathrm{~mm})$. This may result in a work surface that can no longer satisfy the intended population with respect to usability.

\section{EXPERIMENTAL PROCESS}

Given the review of various operational systems and the observed differences in work surface heights, the study objectives were defined to determine if the height of the scanner affected users' performance. Does the height of a scanner platen affect the time required to capture fingerprint images? Does the height of the scanner platen affect the quality of images captured? Finally, are users more comfortable with or do they prefer a particular scanner height?

\subsection{DESIGN AND IMPLEMENTATION}

Fingerprint images were collected from participants at four different standard heights. For each scanner height the participant was asked to leave a left slap (left hand without the thumb), a right slap (right hand without the thumb), each individual thumb print, and both thumb prints together. The four scanner heights corresponded to work table height at 26 inches, desk height at 32 inches, counter height at 36 inches, and standing counter height at 42 inches according to the standards as defined in the architectural design guidelines. Note that the scanner used for this study is six inches high; the effective height of the scanner platen is six inches above the work surface height. The order of the scanner heights and the order of the requested prints were counter-balanced. Participants were randomly assigned (without replacement) to a height and print order. The order of prints and heights were provided to the participants as verbal instructions generated by the software. Each image capture required that the participant leave his/her hand on the scanner for five seconds.

All participants were NIST employees who participated in the study in the course of their official duties with their management's approval. Prior to the collection of the prints, users were asked demographic data including age, gender, handedness, and height. Following the collection, participants were asked preference/satisfaction questions to determine which height was most comfortable and which was least comfortable. All fingerprints, demographic, and satisfaction data were anonymous. 


\subsection{HARDWARE AND SOFTWARE}

The experiment consisted of a digital four-print (slap) fingerprint scanner, custom software that captured images from the fingerprint scanner, and an adjustable shelf system that allowed for the scanner to be positioned at various heights from the floor.

\subsubsection{Digital Fingerprint Scanner}

The digital fingerprint scanner selected for this experiment was the Smiths-Heimann (now CrossMatch) LS2 Check digital fingerprint scanner [SHB]. The LS2 scanner has a large 3.2 inch $\times 2.9$ inch platen $(81 \mathrm{~mm} \times 74 \mathrm{~mm})$ that allows for the capture of one or more fingers simultaneously. The LS2 scanner has a height of 6 inches $(152 \mathrm{~mm})$.

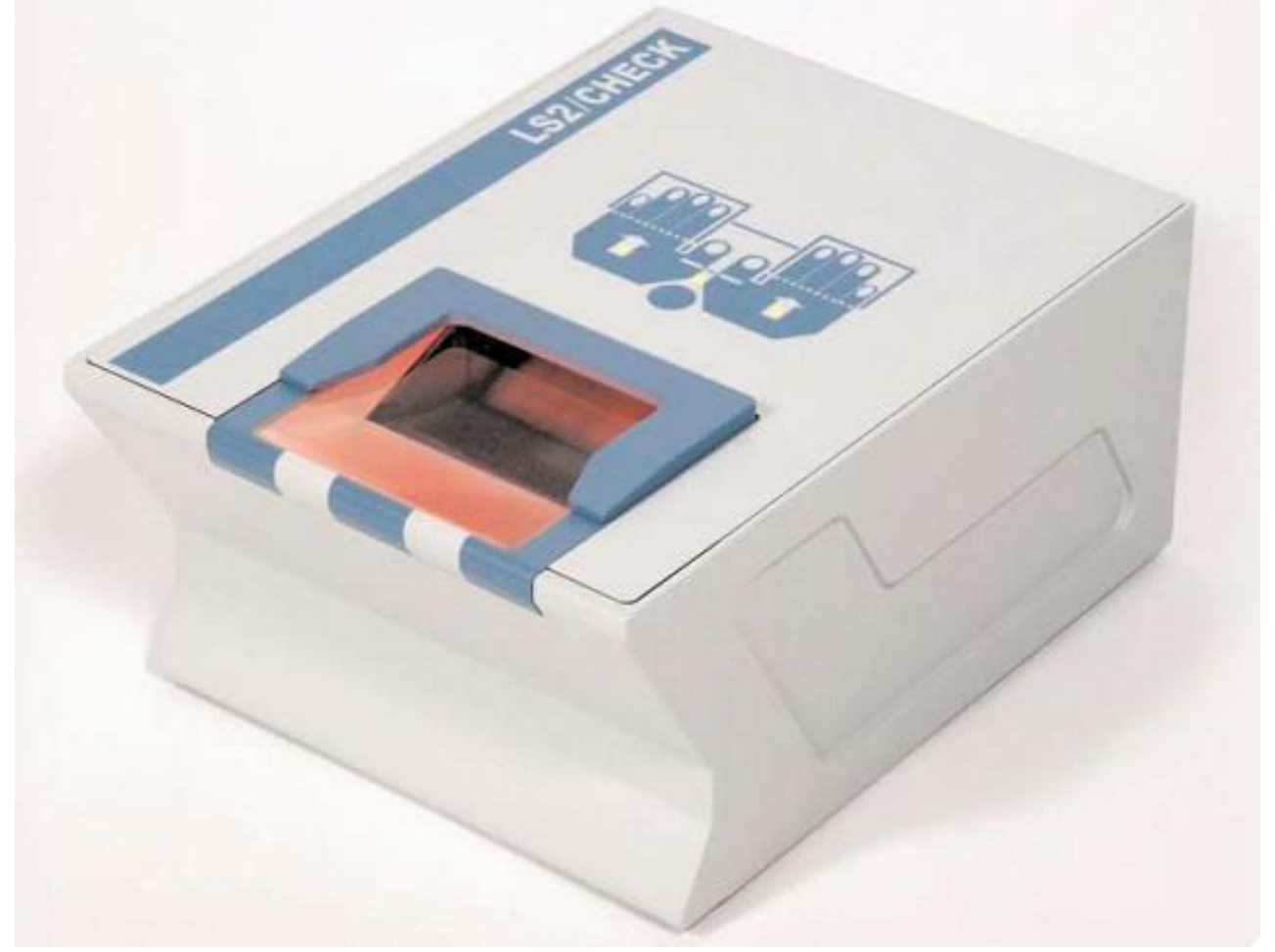

Figure 1: Smiths-Heimann LS2 Check Scanner

\subsubsection{Capture Software}

This experiment utilized a custom capture application that provided for controlled capture of images from a given user at various heights. The custom software's high-level operational flow can be described in the following five steps: 
1) Operator is prompted to adjust the scanner to a particular height

2) Participant is prompted for a hand/finger combination

3) Once the hand/finger is detected images are captured for a set amount of time

4) Repeat step 2 for the next finger/hand combination until all combination are complete

5) Repeat step 1 for any remaining experimental heights

Details of the capture process are provided in the process section of this document (section 4.2.3).

\subsubsection{Process}

The participants were randomly assigned by the software to the height conditions. Before scanning was initiated, the operator adjusted the scanner to a given height and provided participants with verbal instructions. The verbal instruction are included in Appendix B.
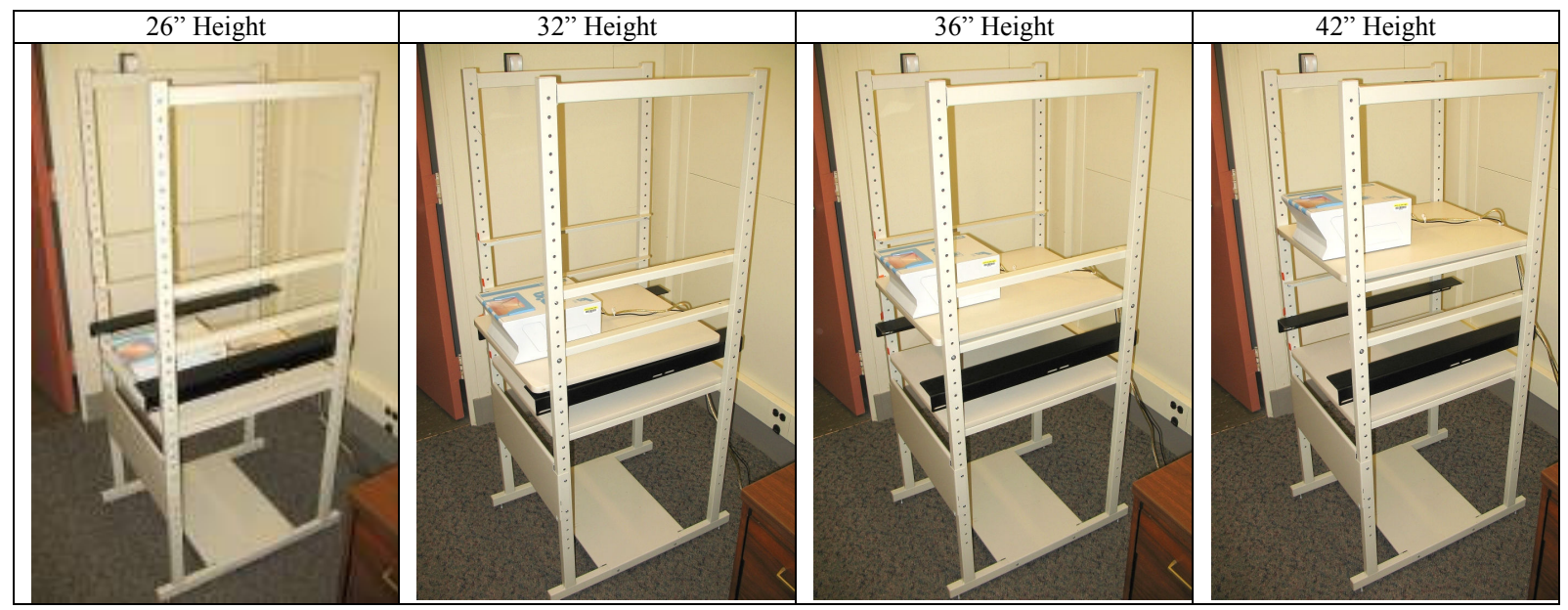

Figure 2: Scanner Test Apparatus Shown in Each of the Four Height Adjustments

Once the adjustments were completed, the operator signaled the start of the trial. The participant listened to the system generated instructions and then placed the appropriate fingers on the platen for collection of prints.

As the audible instructions began, the system simultaneously began the process of precapturing a stream of images. These pre-capture frames were saved in order to record the progression of the state of the scanner platen as the system was waiting for the image of a hand or finger. The pre-capture rate was approximately $0.7 \mathrm{frames} / \mathrm{sec}$ and included the time 
needed by the system to analyze the platen to see if a hand/finger had been placed on the platen (defined as reaching a fixed threshold of coverage on the platen). The pre-capture loop utilizes a circular buffer so if the pre-capture loop had captured 5 images and had not yet detected a finger, the pre-capture loop continued while overwriting the oldest captured detection frame in this 5 image buffer.

Once an image was detected, the system began capturing images as quickly as the scanner could capture them for a predetermined amount of time. The predetermined capture time for this study was set at five seconds, and given the specific hardware configuration of the test system the sustained rate of image capture was approximately 1.5 frames/sec. Typically, a participant yielded one or two pre-capture images and about seven capture images.

At the end of the preset capture period the system stopped capturing images and the participant was instructed to remove his/her hand/finger from the scanner platen. This process was repeated for each task until all of the tasks for a given experimental height had been collected. At the conclusion of all tasks for a given height, the operator manually readjusted the sensor height as necessary for subsequent trial heights. Once all tasks were completed at all heights for a participant, the scanner platen was then cleaned with isopropyl alcohol in preparation for the next participant. 


\section{FINDINGS}

\subsection{PARTICIPANTS}

Seventy-five NIST employees volunteered to participate in this study.

The participants ranged in age from 17 to 67 and were distributed fairly uniformly across the age ranges as shown in Figure 3. The participant pool for this study included 41 men and 34 women.

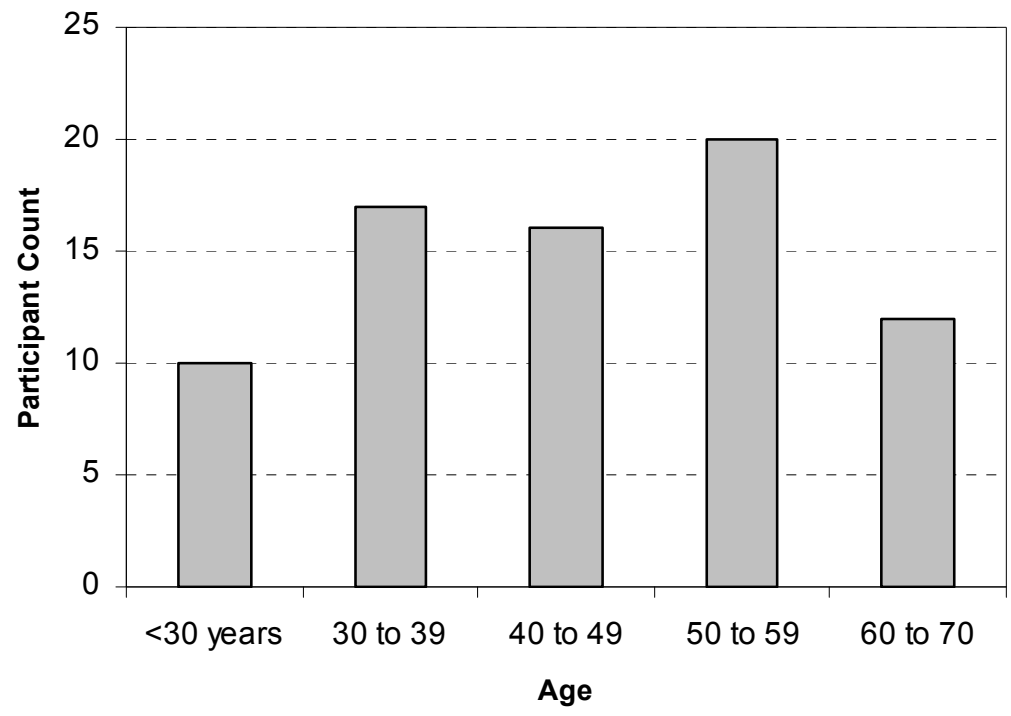

Figure 3: Distribution of Participant Age 
As a reflection of the general population, most of the participants were right-handed (83\%), while $17 \%$ were either left-handed or ambidextrous. Available research shows that approximately $87 \%$ of the general population is right handed and the remaining $13 \%$ of the population is left handed [PORAC]

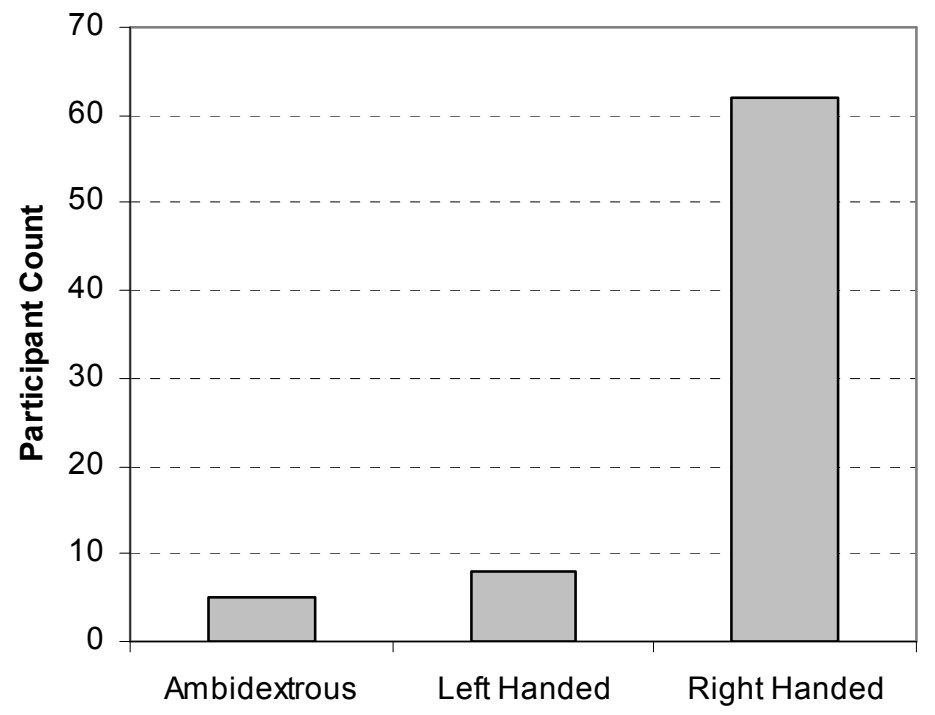

Figure 4: Handedness 
Prior to capturing any fingerprints, we measured the height of each participant with shoes. Participants ranged from 5 feet $(152 \mathrm{~cm})$ to 6 feet 5 inches $(196 \mathrm{~cm})$. The distribution of heights is shown in Figure 5. According to the CDC the mean individual height of men is 5 feet 9 inches $(175 \mathrm{~cm})$ and the mean individual height of women is 5 feet 3 inches $(160 \mathrm{~cm})$ in the US. The height data collected showed that our population mean is within $3 \%$ of the mean individual height of the US general population of males and females respectively [CDC]. According to the World Health Organization the worldwide mean individual male height is 5 feet 8 inches $(173 \mathrm{~cm})$ and the female height is 5 feet 2 inches $(158 \mathrm{~cm})$.

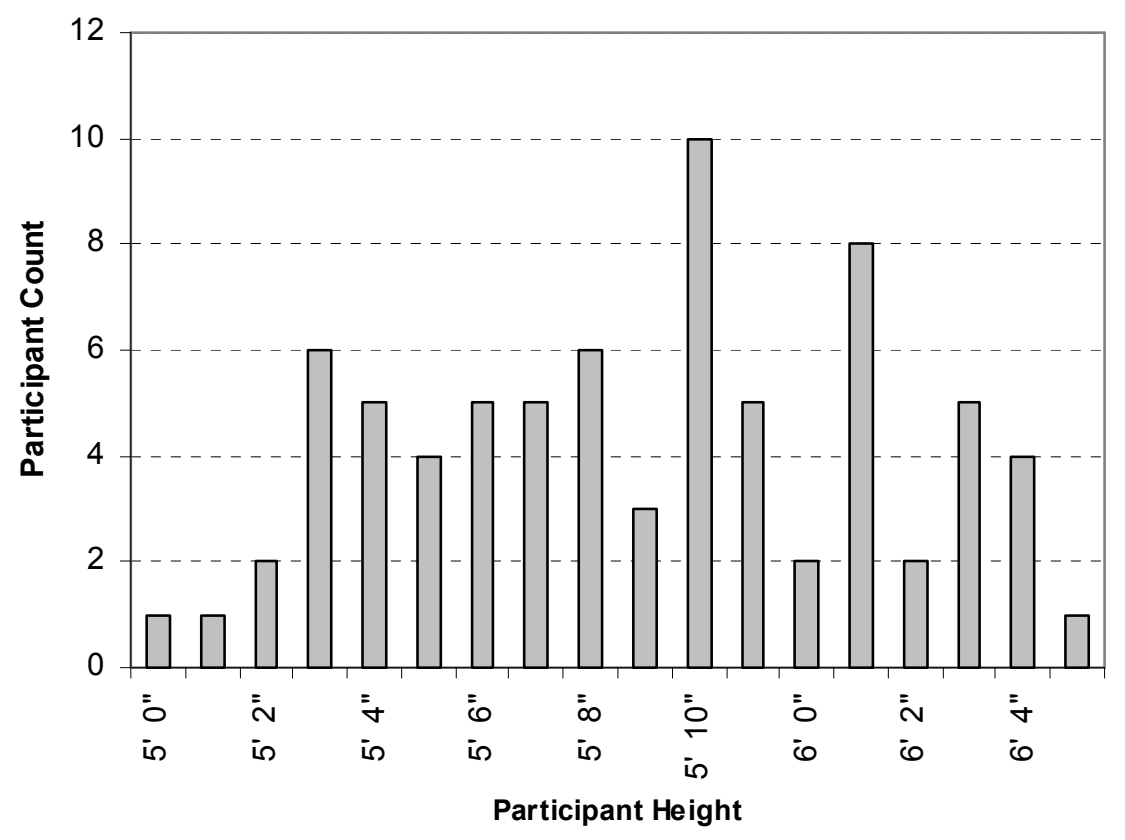

Figure 5: Distribution of Participant's Height 
Before the test began we offered each participant a "practice run" so that they would become comfortable with the capture process. For the practice test they were instructed to place a hand on the scanner, press down, and hold in place until the scanner stopped beeping. For this trial run, we did not explicitly indicate which hand to place on the scanner, so that the unprompted user preference would be observed. We found that 57 participants or $76 \%$ placed their right hand on the scanner, and 18 participants or $24 \%$ placed their left indicating that users are inclined to start with their right hand. This suggests that systems that initiate their capture sequence starting with the left hand runs counter to the populations' natural preference, and therefore may be more error prone.

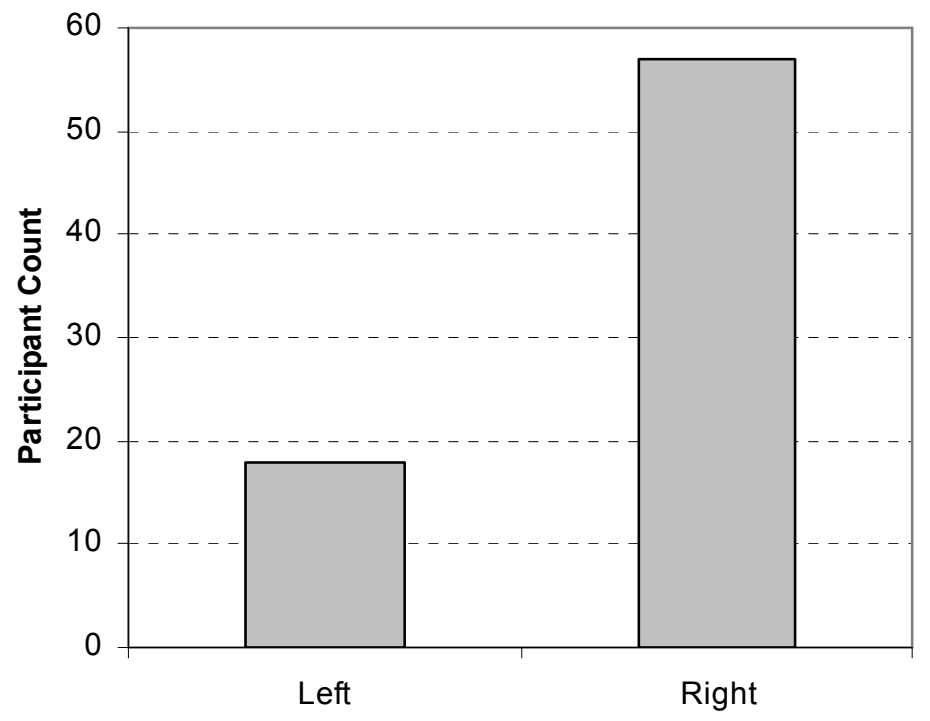

Figure 6: Preferred Starting Hand 


\subsection{USABILITY METRICS}

According to ISO 9241-11 [ISO], usability is defined as "the extent to which a product can be used by specified users to achieve specified goals with effectiveness, efficiency and satisfaction in a specified context of use". The standard identifies three areas of measurement: effectiveness, efficiency, and user satisfaction, where

- effectiveness is a measure of the accuracy and completeness with which users achieve specified goals. Common metrics include completion rate and quality.

- efficiency is a measure of the resources expended in relation to the accuracy and completeness with which users achieve goals. Efficiency is related to productivity and is generally measured as task time.

- user satisfaction is the degree to which the product meets the users' expectations - a subjective response in terms of ease of use, satisfaction, and usefulness.

In this study, we used the ISO definition and measured efficiency, effectiveness, and user satisfaction.

\subsubsection{Efficiency}

In this experiment, we measured efficiency as the time required to complete a task, where a task is defined as a right-slap, left-slap, both thumbs, and single thumbs. Each task was initiated by a voice prompt and the task ended when the system detected that the hand was placed upon the scanner.

We have five response variables denoted by $Y T_{s l}, Y T_{s r}, Y T_{t b}, Y T_{t l}, Y T_{t r}$ corresponding to the left slap (sl), right slap (sr), both thumbs (tb), left thumb (tl), and right thumb (tr) tasks as defined previously. For each fixed response variable (e.g., $\left.Y T_{s l}\right)$ there are two classification variables: (a) work surface height (at levels 1 through 4, from low to high) (b) sex (M or F) as well as two covariates (subject age and subject height). For each response variable, the following analyses were performed. 
The first step taken was to determine if the data was normally distributed. A histogram with a normal probability density plot of task times shows that the data does not follow a normal distribution. This was verified by the Shapiro test for normality.

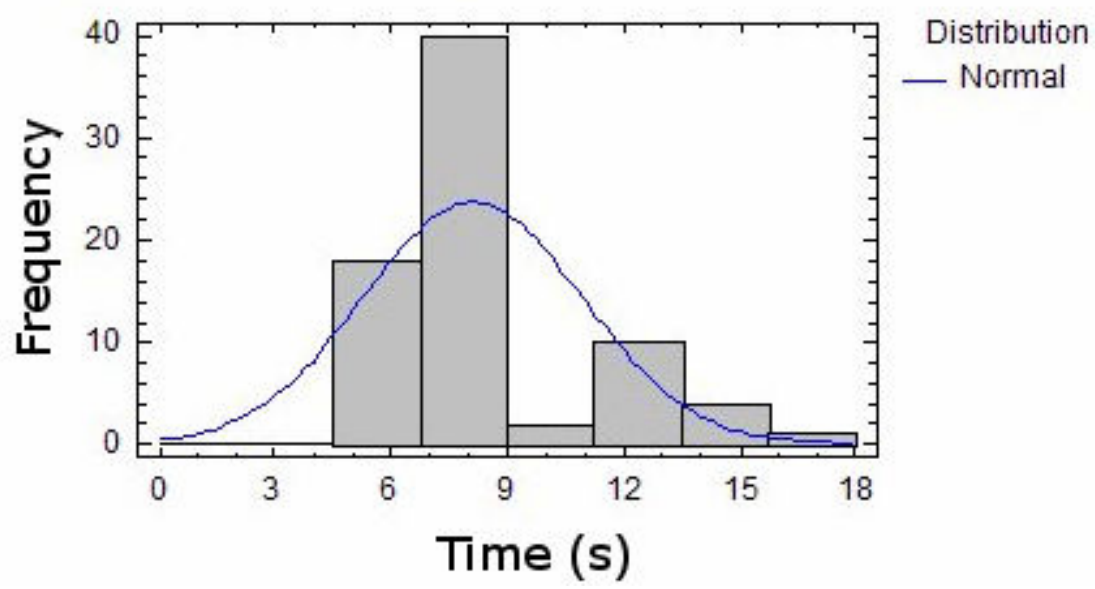

Figure 7: Histogram demonstrating non-normal distribution of data (left slap task example)

Due to the non-normal distribution, a Friedman's two-way non-parametric test was used to test whether the medians are the same. For $Y T_{s r}$, the computed $p$-value of 0.05 indicates a statistically significant difference - not all median times corresponding to the four work surface heights are the same. For the other response variables, no statistically significant differences were found in the test results. 
Figure 8 shows the box plot [TUCKEY]. Points more than three times the interquartile range above or below the box are "far outside points," and are indicated by point symbols with plus signs superimposed on top of them. The medians for the 26,36 , and 42 inch heights are overlapped with the top or bottom lines of the box, and are therefore not visually discernable. The median for the 26 inch height is 7.0 and the lower quartile is also 7.0 - thus the median overlaps with the bottom line of the box. For 36 and 42 inches, the median and upper quartile are also 7.0 and thus, they overlap with the top line of the box.

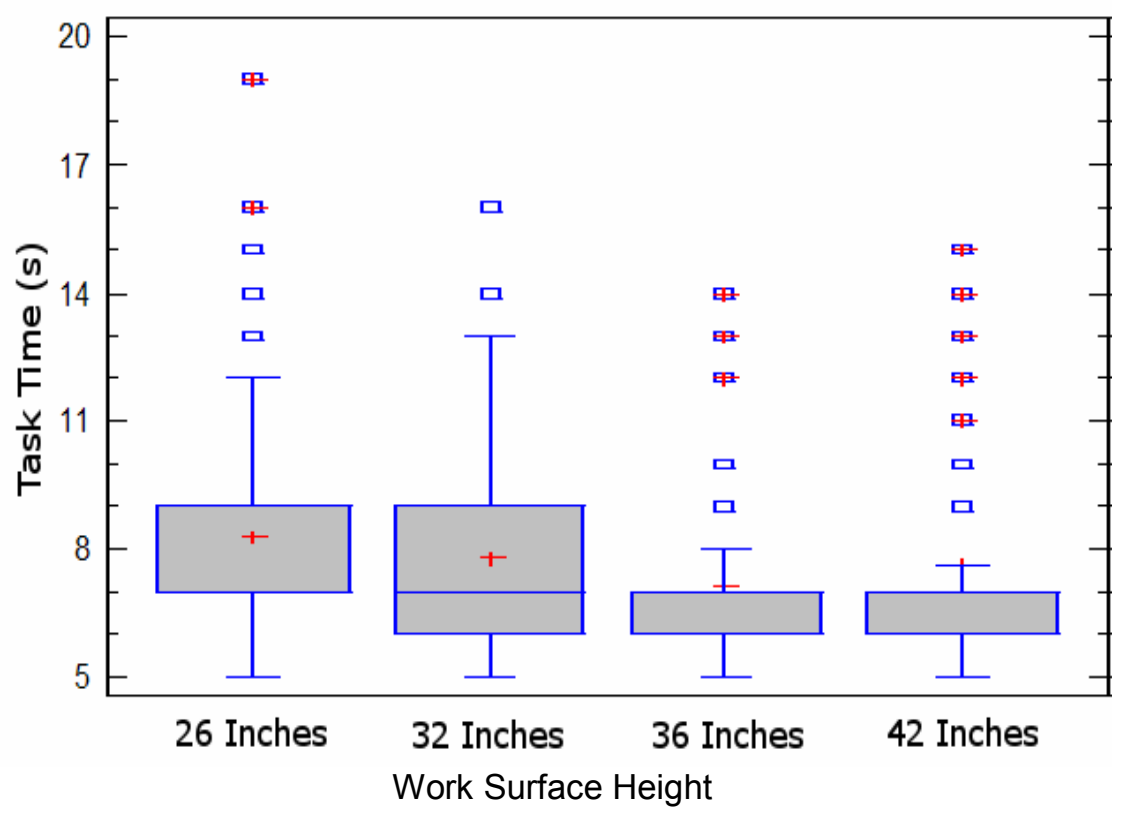

Figure 8: Box Plot for Right-Slap Task 
To investigate the detailed relationship among the work surface heights, we used pair wise comparisons based on sign and signed rank tests for $Y T_{s r}$. Pair wise comparisons test whether the median of the differences of each pair is zero. The results are as summarized in Table 1.

\begin{tabular}{|l|l|l|l|l|}
\hline & $26 ”$ & $32 ”$ & $36 ”$ & $42 "$ \\
\hline $26 ”$ & & $p=0.13(p=0.25)$ & $p=0.03(p<0.01)$ & $p=0.27(p=0.21)$ \\
\hline $32 ”$ & $p=0.13(p=0.25)$ & & $p=0.41(p=0.15)$ & $p=0.78(p=0.72)$ \\
\hline $36 ”$ & $p=0.03(p<0.01)$ & $p=0.41(p=0.15)$ & & $p=0.09(p=0.06)$ \\
\hline $42 ”$ & $p=0.27(p=0.21)$ & $p=0.78(p=0.72)$ & $p=0.09(p=0.06)$ & \\
\hline \multicolumn{5}{|c}{ Cell Legend: Sign Test (Signed Rank Test), and shaded cells indicate statistically significant pairs. } \\
\hline
\end{tabular}

Table 1: Pairwise comparisons for right slap task

Thus, for the pairwise comparisons, only the median times for work surfaces at 26 inches and 36 inches are different and significant with participants performing faster at the 36 inch work surface height. This result is also consistent with multiple range tests [DUNCAN]. 
Combining the response variables results provides another view of the data as illustrated in Table 2.

\begin{tabular}{|c|c|c|c|c|c|c|c|c|c|c|c|c|c|c|c|}
\hline \multirow[b]{2}{*}{ 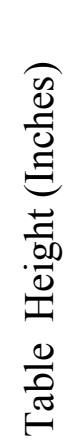 } & \multicolumn{3}{|c|}{$Y T_{s l}$} & \multicolumn{3}{|c|}{$Y T_{s r}$} & \multicolumn{3}{|c|}{$Y T_{t b}$} & \multicolumn{3}{|c|}{$Y T_{t l}$} & \multicolumn{3}{|c|}{$Y T_{t r}$} \\
\hline & $\begin{array}{l}\underset{0}{\Xi} \\
\underset{\Xi}{\Xi} \\
\sum\end{array}$ & 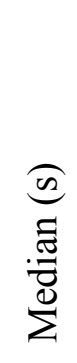 & 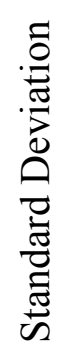 & $\begin{array}{l}\underset{0}{\Xi} \\
\underset{\Xi}{\Xi} \\
\sum\end{array}$ & 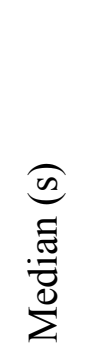 & 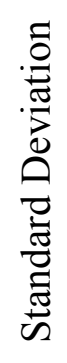 & $\begin{array}{l}\underset{0}{\Xi} \\
\underset{\Xi}{\Xi} \\
\sum\end{array}$ & 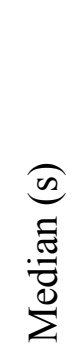 & 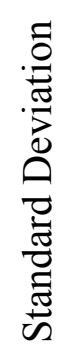 & 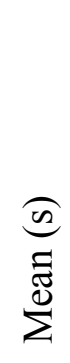 & 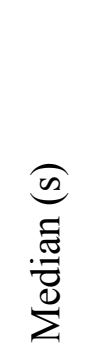 & 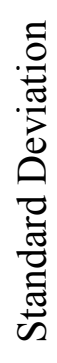 & $\begin{array}{l}\underset{0}{\Xi} \\
\underset{\Xi}{\Xi} \\
\sum\end{array}$ & 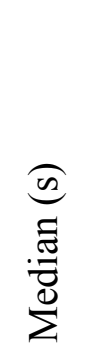 & 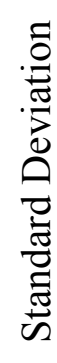 \\
\hline $26^{\prime \prime}$ & 8.1 & $7(1)$ & 2.9 & 8.3 & $7(2)$ & 3.2 & 8.0 & $7(0)$ & 2.6 & 8.1 & $7(3)$ & 2.8 & 7.8 & $7(1)$ & 3.3 \\
\hline $32 "$ & 7.5 & $7(2)$ & 2.3 & 7.8 & $7(3)$ & 2.8 & 7.5 & $7(2)$ & 2.5 & 7.9 & $7(2)$ & 3.6 & 8.2 & $7(4)$ & 3.4 \\
\hline $36 "$ & 7.5 & 7 (1) & 2.3 & 7.2 & $7(1)$ & 2.1 & 8.1 & $7(4)$ & 2.8 & 7.5 & $7(3)$ & 2.8 & 7.7 & $7(2)$ & 3.3 \\
\hline $42 ”$ & 7.9 & $7(2)$ & 2.6 & 7.7 & $7(1)$ & 2.6 & 8.1 & $7(2)$ & 2.8 & 7.5 & $7(2)$ & 2.9 & 8.6 & $7(3)$ & 4.6 \\
\hline
\end{tabular}

The numbers in the parentheses associated with the medians are the interquartile ranges and shaded cells indicate an optimum value (lowest time, highest efficiency) for a given column at a particular work surface height.

Legend:

\begin{tabular}{|l|}
\hline Task \\
\hline SL - Left Slap \\
\hline SR - Right Slap \\
\hline TB - Both Thumbs \\
\hline TL - Left Thumb \\
\hline TR - Right Thumb \\
\hline
\end{tabular}

Table 2: Mean, Median and Standard Deviation Calculations for Capture Efficiency

Although the table height is not a statistically significant factor for the response variables except in $Y T_{s r}$, the response variables at a table height of 36 inches overall have the smallest means, smallest standard deviations, smallest medians and smallest interquartile ranges.

However, for operational completeness, we also consider the average time per task to complete a sequence of tasks. Combining $Y T_{s l}$ and $Y T_{s r}$ yields.

$Y T_{a s l r}=\frac{Y T_{s l}+Y T_{s r}}{2}$ 
Similarly,

$Y T_{a t r}=\frac{Y T_{t l}+Y T_{t r}}{2}$

$Y T_{a t b l r}=\frac{Y T_{t b}+Y T_{t l}+Y T_{t r}}{3}$

and the overall mean $Y T_{\text {aall }}=\frac{Y T_{s l}+Y T_{s r}+Y T_{t b}+Y T_{t l}+Y T_{t r}}{5}$

\begin{tabular}{|c|c|c|c|c|c|c|c|c|c|c|c|c|}
\hline \multirow[b]{2}{*}{ 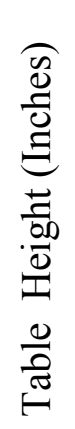 } & \multicolumn{3}{|c|}{$Y T_{a s l r}$} & \multicolumn{3}{|c|}{$Y T_{a t r}$} & \multicolumn{3}{|c|}{$Y T_{a t b l r}$} & \multicolumn{3}{|c|}{$Y T_{\text {aall }}$} \\
\hline & 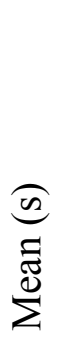 & 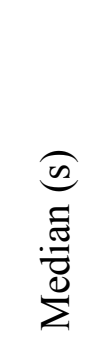 & 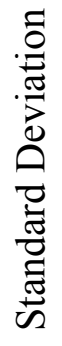 & 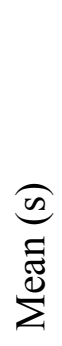 & 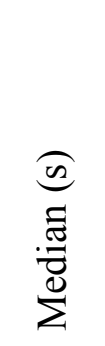 & 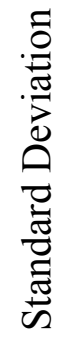 & 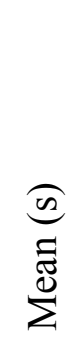 & 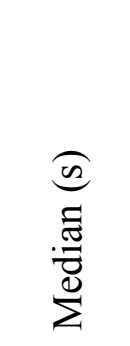 & 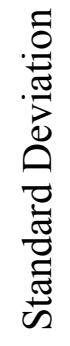 & 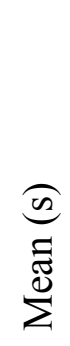 & 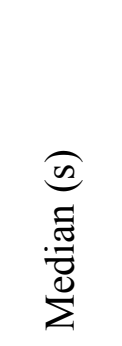 & 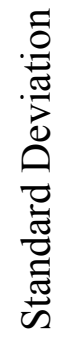 \\
\hline $26 "$ & 8.2 & $7(3.5)$ & 2.4 & 8.0 & $7(2.5)$ & 2.0 & 7.9 & $7.0(2.3)$ & 1.8 & 8.0 & $7.8(2.2)$ & 1.6 \\
\hline $32 "$ & 7.7 & $7(2)$ & 1.9 & 7.7 & $7(3)$ & 2.2 & 7.9 & $7.3(2.3)$ & 2.2 & 7.8 & $7.4(1.6)$ & 1.6 \\
\hline $36 "$ & 7.3 & $7(2)$ & 1.6 & 7.8 & $7(3.5)$ & 2.1 & 7.8 & $7.3(2.7)$ & 2.0 & 7.6 & $7.4(1.4)$ & 1.4 \\
\hline & 7.8 & $7(3.5)$ & 2.1 & 7.8 & $7(4)$ & 2.1 & 8.1 & $7.3(2.7)$ & 2.4 & 8.0 & $7.6(2)$ & 1.9 \\
\hline
\end{tabular}

The numbers in the parentheses associated with the medians are the interquartile ranges and shaded cells indicate an optimum value (lowest time, highest efficiency) for a given column at a particular work surface height.

Table 3: Sequence-Based Mean, Median and Standard Deviation Calculations for Capture Efficiency

The partial sums were selected to further explore the influence of the right slap task on overall timing. Table 3 again suggests that although the work surface height is not a statistically significant factor for the response variables except in $Y T_{s r}$, the response variables at work surface height of 36 inches overall have smallest means, smallest standard deviations, smallest medians and smallest interquartile ranges.

In summary, the data indicate that given a six-inch tall sensor, any ten-print capture sequence that includes a right-slap is most efficient at a work surface height of 36 inches. 


\subsubsection{Effectiveness}

The analysis of the effect of sensor height effectiveness is based on image quality as formally defined by the NIST Fingerprint Image Quality metric, or NFIQ [NISTSW].

Analysis of quality began by taking each captured image and processing that image with the NIST Fingerprint Image Software 2 (NFIS2) [NISTSW] segmenter. ${ }^{4}$ (Pre-capture images were not considered in the quality analysis.) The NFIS2 segmenter "breaks apart" an image of multiple fingers into individual finger images. For example, transforming a slap into separate index, middle, ring and little finger images. Next, the NFIQ score for each segmented finger was computed. The NFIQ algorithm generates scores ranging from one (highest quality) to five (lowest quality). Missing image data was assigned a quality score of five - the lowest NFIQ value. Multiple images were captured for each task sequence over a specified period of time (see section 4.2.3 for details of the capture process). This image capture process yielded approximately 360 finger images per subject across all heights and tasks, or approximately 27,000 images total for all subjects who participated in the experiment.

Since there is no generally accepted method to determine the quality of a slap overall, this study examined the distribution of the frequency of NFIQ scores for each finger. The analysis used the Federal Bureau of Investigation (FBI) numbering for fingers for the right and left slaps, and the individual thumbs task. For the simultaneous thumbs task the right thumb was assigned to 11 and the left thumb was assigned to 12 as indicated in Figure 9.

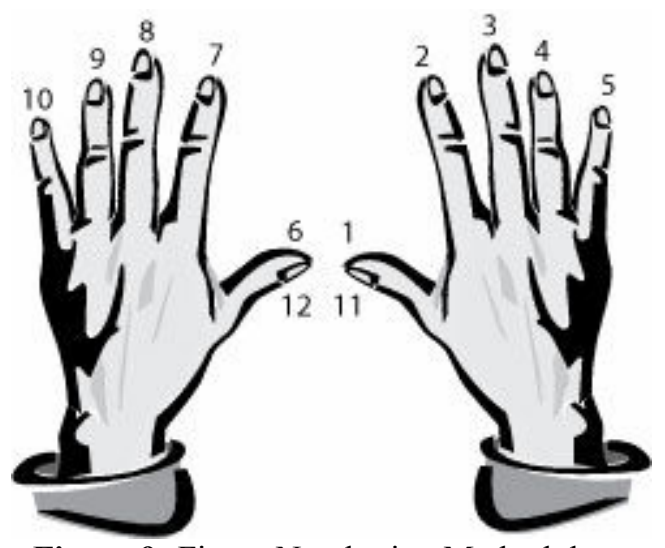

Figure 9: Finger Numbering Methodology

${ }^{4}$ Modified to better accommodate images from livescan sensor with a 3" x 3" $(76.2 \mathrm{~mm}$ x $76.2 \mathrm{~mm}$ ) active sensing area. 
Once the frequencies were computed for each finger across the table heights a chi-square test was used to investigate the significance of the differences among the distributions of quality scores. We found that the differences between the observed and expected frequencies are reliable for all fingers except the right index finger. Meaning for all other fingers the distribution is not the same across the table heights. Since the right index finger is the only finger where no reliable difference was found, this suggests that the distributions are the same. Table 4 provides the $\chi^{2}$ values for all of the fingers. Figure 10 shows the distribution for the right index finger. Appendix $\mathrm{C}$ contains the tables and $\chi^{2}$ values for all of the fingers as well as the graphs of the distributions.

\begin{tabular}{|l|r|l|}
\hline Finger & $\chi^{2}$ Value & Probability \\
\hline 1 Right Thumb Solo & 6.3 & $p=0.0000$ \\
\hline 2 Right Index & 17.66 & $p=0.1263$ \\
\hline 3 Right Middle & 23.67 & $p=0.0200$ \\
\hline 4 Right Ring & 30.24 & $p=0.0026$ \\
\hline 5 Right Little & 23.2 & $p=0.0260$ \\
\hline 6 Left Thumb Solo & 49.97 & $p=0.0000$ \\
\hline 7 Left Index & 25.02 & $p=0.0150$ \\
\hline 8 Left Middle & 44.98 & $p=0.0000$ \\
\hline 9 Left Ring & 26.5 & $p=0.0091$ \\
\hline 10 Left Little & 25.88 & $p=0.0150$ \\
\hline 11 Right Thumb Both & 60.16 & $p=0.0000$ \\
\hline 12 Left Thumb Both & 61.01 & $p=0.0000$ \\
\hline \multicolumn{2}{|c|}{$d f=12=(5-1)^{\star}(4-1)$} \\
\hline
\end{tabular}

Table 4: $\chi^{2}$ Values for Each Finger Across Heights

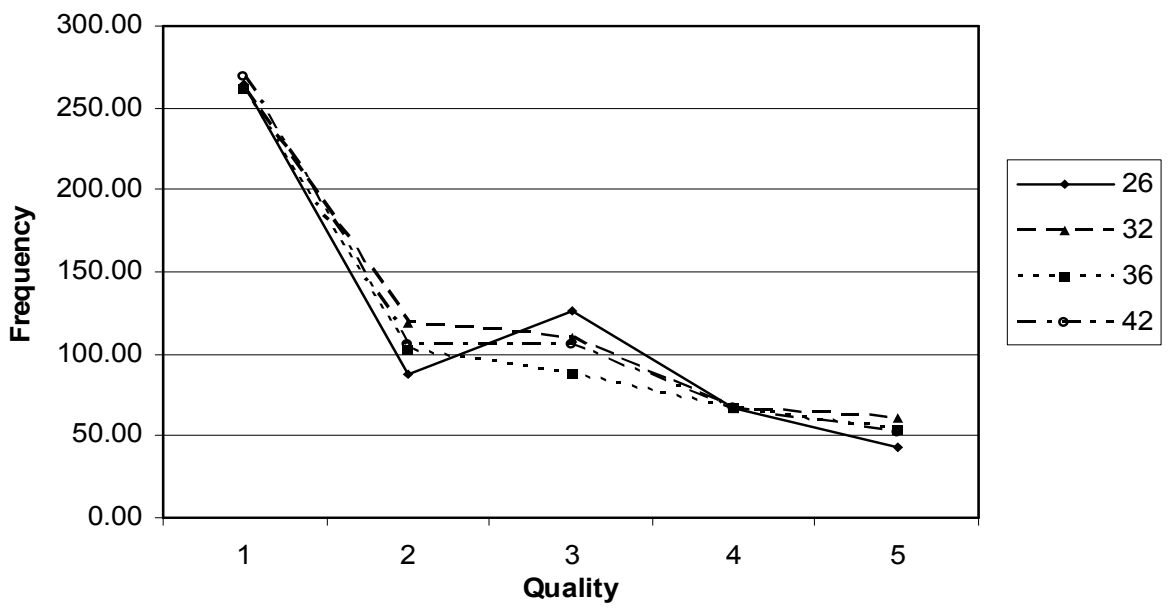

Figure 10: Right Index Finger Quality Distribution 
To investigate the relationship among the work surface heights, we used pairwise comparisons with chi-square for those fingers where the distribution was reliable. The results are summarized in Table 5 for the left hand and Table 6 for the right hand. In order to investigate the change in quality for each height pair, we determined the difference between the percentage of NFIQ 1's and 2's and the percentage of NFIQ 4's and 5's for that finger at a specific height. Comparing these values across the heights provides an indication of an increase or decrease in quality from one height to another. This change in quality is denoted by an arrow. In the following tables, an arrow up ( $\boldsymbol{\uparrow})$ indicates improvement in quality while an arrow down $(\boldsymbol{\Downarrow})$ indicates a degradation in quality. As an example consider finger number 6 and heights 42 and 36. The difference for the 42 inch height is $35 \%$ and the difference for the 36 inch height is $43 \%$. Since $43 \%$ is greater than $35 \%$, the quality is better at the 36 inch height and is indicated by the up arrow in the following table. The complete tables of the percentages can be found in Appendix C.

\begin{tabular}{|c|c|c|c|c|c|c|}
\hline $\begin{array}{c}\text { Left Hand } \\
\text { Finger Number }\end{array}$ & $42 " \rightarrow 36 "$ & $42 " \rightarrow 32 "$ & $42 " \rightarrow 26 "$ & $36 " \rightarrow 32 "$ & $36 " \rightarrow 26 "$ & $32 " \rightarrow 26 "$ \\
\hline 6 & $p<<0.05$ 个 & $p<<0.05$ 个 & $p<<0.05$ 个 & $p=0.36$ & $p=0.92$ & $p=0.21$ \\
\hline 12 & $p=0.08$ & $p<<0.05$ ト & $p<<0.05$ 个 & $p<<0.05$ 个 & $p=0.006$ 个 & $p=0.24$ \\
\hline 7 & $p=0.03 \downarrow$ & $p=0.003$ 个 & $p=0.245$ & $p=0.36$ & $p=0.47$ & $p=0.069$ \\
\hline 8 & $p<<0.05$ イ & $p=0.009$ イ & $p=0.0004$ ト & $p=0.015$ 个 & $p=0.009$ 个 & $p=0.15$ \\
\hline 9 & $p=0.02$ 个 & $p=0.04$ 个 & $p=0.01$ 个 & $p=0.25$ & $p=0.79$ & $p=0.05$ 个 \\
\hline 10 & $p=0.27$ & $p=0.58$ & $p=0.0069$ ヘ & $p=0.19$ & $p=0.008$ 个 & $p=0.02$ 个 \\
\hline
\end{tabular}

Table 5: Pairwise Comparisons for Left Hand Fingers(shaded cells indicate a reliable difference, arrow up/down indicates an improvement/degradation in quality at this interaction)

\begin{tabular}{|c|c|c|c|c|c|c|}
\hline $\begin{array}{c}\text { Right Hand } \\
\text { Finger Number }\end{array}$ & $42 " \Leftrightarrow 36 "$ & $42 " \Leftrightarrow 32 "$ & $42 " \Leftrightarrow 26 "$ & $36 " \Leftrightarrow 32 "$ & $36 " \Leftrightarrow 26 "$ & $32 " \Leftrightarrow 26 "$ \\
\hline 1 & $p<<0.05 \downarrow$ & $p=0.897$ & $p=0.002 \downarrow$ & $p<<0.05$ 个 & $p<<0.05 \uparrow$ & $p=0.004$ 个 \\
\hline 11 & $p=0.0005$ 个 & $p<<0.05$ 个 & $p<<0.05$ 个 & $p=0.12$ & $p=0.15$ & $p=0.06$ \\
\hline $2^{* 5}$ & - & - & - & - & - & - \\
\hline 3 & $p=0.02 \downarrow$ & $p=0.42$ & $p=0.40$ & $p=0.01$ 个 & $p=0.007$ 个 & $p=0.99$ \\
\hline 4 & $p=0.37$ & $p=0.006 \downarrow$ & $p=0.28$ & $p=0.001 \uparrow$ & $p=0.089$ & $p=0.066$ \\
\hline 5 & $p=0.03$ 个 & $p=0.43$ & $p=0.07$ & $p=0.15$ & $p=0.02$ 个 & $p=0.36$ \\
\hline
\end{tabular}

Table 6: Pairwise Comparisons for Right Hand Fingers (shaded cells indicate a reliable difference, arrow up/down indicates an improvement/degradation in quality at this interaction)

${ }^{5}$ No reliable difference was calculated for this finger at all heights. 
Based on the frequency of statistical significance (the shaded cells in Tables 5 and 6), the following trends are revealed:

- The right index finger was not sensitive to height. The right index finger is the only finger where no reliable difference was found, suggesting that the distributions are the same.

- The thumbs appear to be more sensitive to height than the slaps.

- The left slap appears to be more sensitive than the right slap.

Examining those table entries of statistical significance induces a partial ordering for a \{left slap, right slap, both thumbs\} sequence where the edges correspond to a statistically significant test where one height was found to be more or less effective than another height. Edges are directed from less effective to more effective. These orderings suggest the following recommendations for optimal scanner placement with respect to counter height:

- For the simultaneous thumb print:

The work surface height yielding the poorest image quality was 42 inches. Participants were consistently able to provide higher quality thumbprints at work surface heights lower than 42 inches. The work surface height yielding the highest image quality is at 26 or 32 inches.

- For the left slap:

The work surface height yielding the poorest image quality was 42 inches.

Participants were consistently able to provide higher quality prints at work surface heights lower than 42 inches. The work surface height yielding the highest image quality is at 26 inches.

- For the right slap, there were no clear trends.

- For the individual thumbs, there were no clear trends.

Finally, Table 19 and Table 20 show a dramatic drop in quality from individual thumbprints to simultaneous thumbs. This observation suggests that individual thumbs give higher quality images across all heights. Further study is required to understand this difference in the thumbs quality. 


\subsubsection{User Satisfaction}

Each user was given a satisfaction survey after completing the test (See Appendix A for the actual questionnaire). The questions included:

1. Which scan height did you find most comfortable?

2. Which scan height did you find most uncomfortable?

3. Please rank the heights in order of preference: 1 is most preferred, 4 is least preferred

4. When prompted for your thumbs, which method did you prefer?

5. Did you have difficulty repositioning yourself for any of the trials?

6. Any additional comments on how we can improve the fingerprint capture process?

Overall, the participants clearly found the 32 inches and 36 inches heights the most comfortable as illustrated in Figure 11.

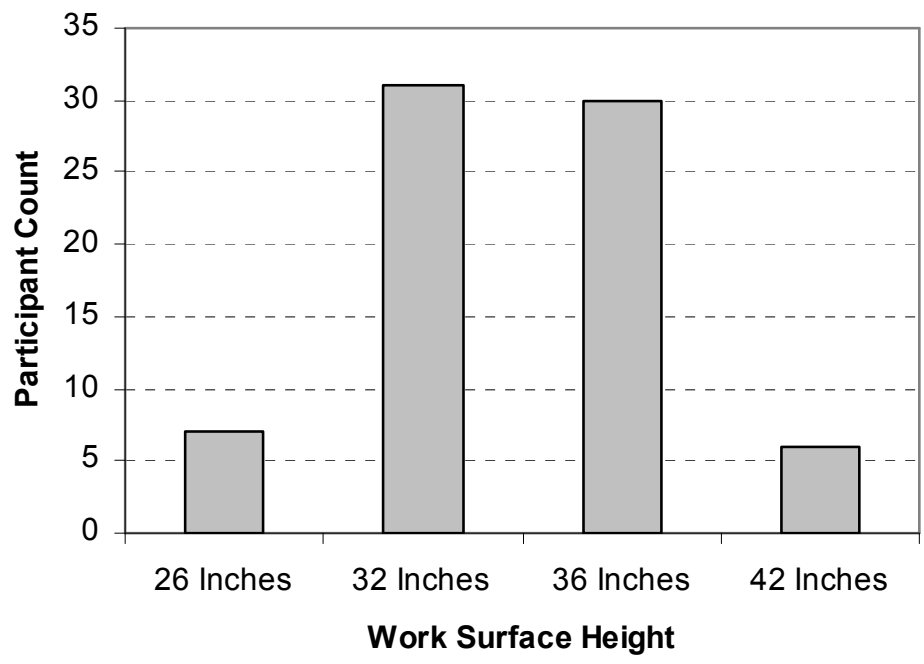

Figure 11: Most Comfortable Work Surface Height

They found the work surface at 42 inches to be the most uncomfortable as shown Figure 12 . One user commented, that "you need significant arm strength at 42 inches even standing on toes." We observed several participants stand on tip toes to position themselves at the work surface height of 42 inches. Another participant indicated that due to arthritis they couldn't press down hard enough at the highest height. 
In response to "Did you have difficulty repositioning yourself for any of the trials?", of the 75 participants, 45 commented that the work surface height of 42 inches was especially difficult for positioning both thumbs. They also indicated that it was uncomfortable for both thumbs. Comments included that "[...] this is awkward [...]" and "[...] kind of hard."

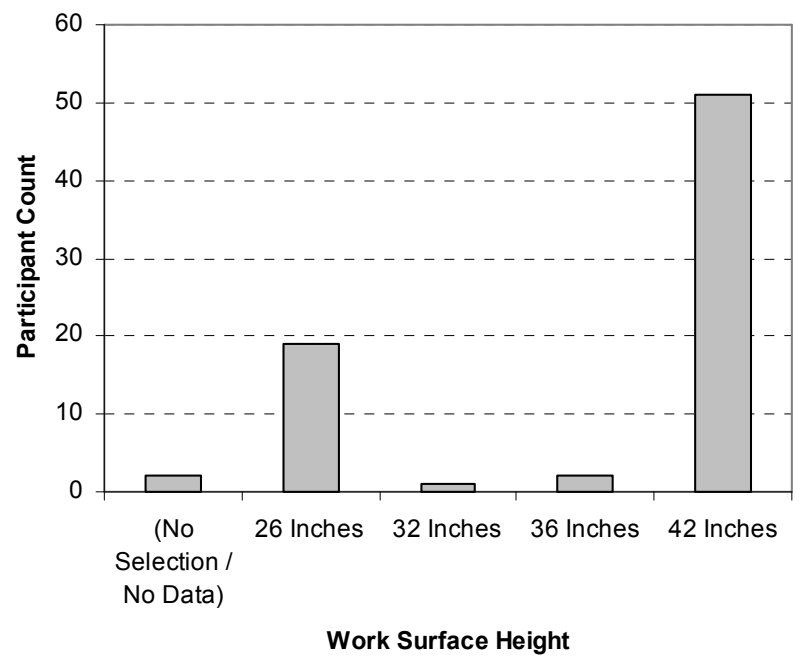

Figure 12: Most Uncomfortable Height 
Rankings also suggested that the users preferred the work surface at 32 inches (Figure 13).

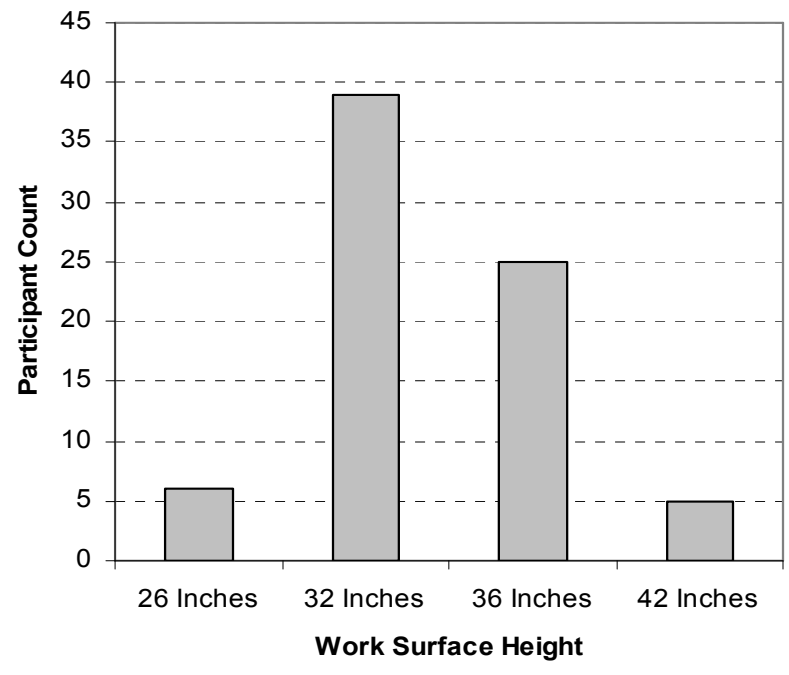

Figure 13: Most Preferred Height From Rankings

Users had no significant preference between both thumbs or one thumb at a time (Figure 14). Several users who preferred both thumbs indicated that they chose both thumbs since it was faster than one thumb at a time.

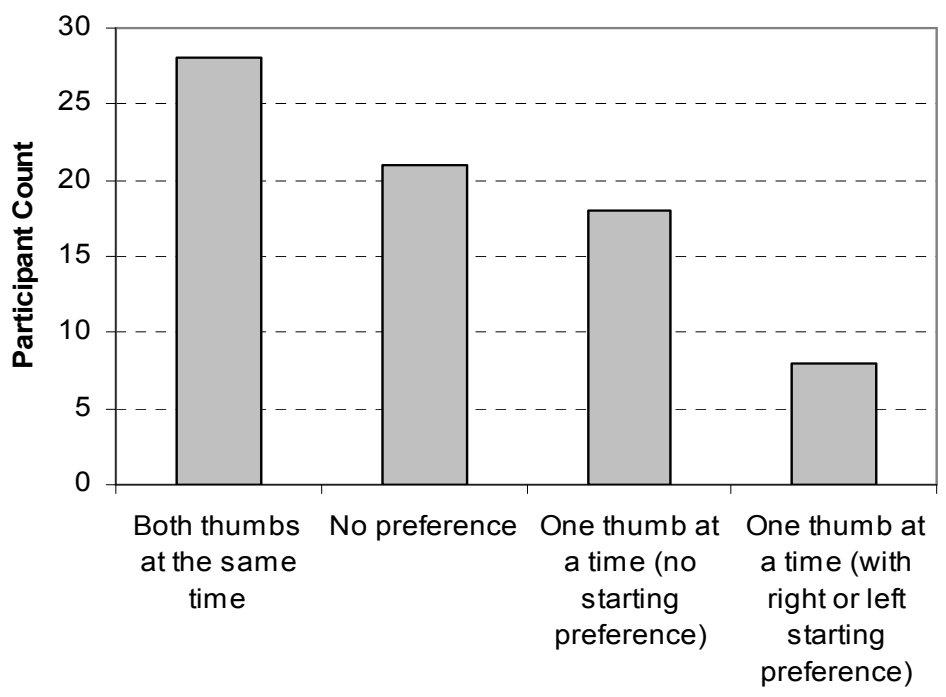

Figure 14: Thumb Preference 


\section{RECOMMENDATIONS AND CONCLUSIONS}

This study compared work surface heights of 26, 32, 36 and 42 inches not including the height of the scanner. In this study, we used a scanner that was 6 inches high resulting in a scanner platen height that was 6 inches above the work surface. In addition, this study was performed in a controlled environment. This controlled environment did not attempt to simulate a point of entry environment or the stress associated with traveling and encountering the fingerprint process.

In this study we observed four main results with respect to the following tasks:

- A left slap (all fingers on the left hand except for the thumb)

- A right slap (all fingers on the right hand except for the thumb)

- Individual thumb prints (a left thumb or right thumb)

- Simultaneous thumb prints (both thumbs)

First, we found that the work surface height does affect how quickly a person can complete the task - in particular, a sequence that includes a right slap. There is a significant difference in completion time of the right slap from 36 inches to 26 inches. In general, participants performed faster at the 36 inch work surface height. Although in absolute terms the difference in time is small, this small improvement in the user's ability to provide prints could translate to a meaningful savings in time when processing a large number of people.

Second, quality or effectiveness, is also affected by the height of the work surface. The thumbs appear to be more sensitive to height than either the right or left slaps. In addition, there is a dramatic drop in quality from individual thumbprints to simultaneous thumbs. This observation suggests that individual thumbs give higher quality images across all heights. The left slap appears to be more sensitive to height than the right slap. For left slap participants were consistently able to provide higher quality prints at work surface heights lower than 42 inches. The work surface height yielding the highest image quality is at 26 inches. This trend was also true for the simultaneous capture of both thumbs, the participant's fingerprint quality decreased as the height of the work surface increased. Thus at the 26 inch or 32 inch work surface, participants left better quality thumbprints. This is consistent with the participants' overall claimed and observed discomfort of placing both thumbs at an effective 48 inch high sensor platen (resulting from placing a 6 inch high scanner on a 42 inch high work surface).

Third, participants clearly preferred the 32 inch work surface and were the most uncomfortable at the 42 inch height. There appears to be a relationship between the participant's discomfort response to the 42 inch height and the quality of the captured prints. 
Over half of the participants commented that it was difficult, awkward, or uncomfortable to position their two thumbs at 42 inches and the data indicates that quality degrades for both thumbs as the work surface height increases.

Finally, we observed that when given a choice $76 \%$ of the participants would start the capture process with their right hand. The timing results also showed a significant difference for the right slap task. These two observations suggest that systems that initiate their capture sequence starting with the right hand might be less error prone and faster than a process that does not follow the populations' natural preference.

To summarize, the following conclusions can be reached, given a 6-inch scanner:

1. Thirty-six inches is the most efficient work surface height (i.e., lowest average capture times). for a capture sequence that includes the right slap.

2. Twenty-six inches is the most effective (i.e., highest average image quality) heights for a capture sequence that includes simultaneous thumbs and a left slap.

3. Users are most satisfied with a work surface height of 32 or 36 inches.

4. Start the sequence with the right hand.

5. Capture individual thumbs instead of simultaneous thumbs.

Given all considerations, placement of a scanner on a 42 inch work surface or higher does not satisfy the goals of efficiency, effectiveness or satisfaction, and therefore should not be considered as a viable height for scanner placement.

\section{REFERENCES}

[911COM1] "Summary of Recommendations", Final Report of the National Commission on Terrorist Attacks Upon the United States (The 9/11 Commission Report), B-303692, 2004.

[AGS] Ramsey, Charles George and Harold Reeve Sleeper. "Architectural Graphic Standards", New York, John Wiley \& Sons, Inc., 1994. Ninth Edition: p 3-5.

[CDC] "Advanced Data From Vital and Health Statistics", US Department of Health and Human Services Centers for Disease Control and Prevention, October 27, 2004, http://www.cdc.gov/nchs/data/ad/ad347.pdf 
[CROSS] "Cross Match ID 1000 10-Print Live Scan System Specifications", Cross Match Corporation, 2005, http://www.crossmatch.com/pdf/ID_1000_final.pdf

[DUNCAN] Duncan, D.B., "Multiple Range and Multiple F Tests", Biometrics, Vol. 11, No. 1, 1955.

[IDENTIX] “TouchPrint Enhanced Definition 3000 Live Scan Specifications", Identix Corporation, 2005, http://www.identix.com/products/pro_livescan_3000 ts.html

[ISO] "Ergonomic requirements for office work with visual display terminals (VDTs) - Part 11: guidance on usability", ISO 9241-11, 1998.

[JAIN1] Jain, Anil K., "Multimodal User Interfaces: Who's the User", http://icmi.cs.ucsb.edu/Misc/JainSlides.pdf , 2003, p 9.

[M1/05-0306] "Biometric Sample Quality Standard Draft" (Revision 4), M1/050306, 6 May 2005.

(http://www.incits.org/tc home $/ \mathrm{m} 1 \mathrm{htm} / \mathrm{docs} / \mathrm{m} 1050306 . \mathrm{pdf})$

[M1472] "Human Engineering Design Criteria for Military Systems, Equipment and Facilities" (Revision D), MIL-STD-1472, 14 March 1989, p 154.

[M759] "Handbook for Engineering Design Guidelines" (Revision C), MIL-HDBK-759C, 31 July 1995, p 143.

[LATTA] N. Latta, "10 Print Scanner Impacts”, U.S. Department of Homeland Security, October 14, 2005, http://www.itl.nist.gov/iad/894.03/pact/10pWS/10pWS03DHS_Latta_Williams.pdf.

[NISTSW] M.D. Garris, C.I. Watson, R.M. McCabe, C.L. Wilson. User's guide to NIST fingerprint image software. NISTIR 6813. http://fingerprint.nist.gov/NFIS/index.html

[PORAC] C. Porac and S. Coren. "Lateral Preferences and Human Behavior”, New York, Springer-Verlag, 1981. 
$[\mathrm{SHB}]$

"Smiths-Heimann LS2 Check Scanner Specifications", Cross Match Corporation, 2005, http://www.shb-

jena.com/Products/LS2_CHECK.pdf

[TUKEY] Tukey, J. W., "Exploratory Data Analysis", Reading, Massachusetts, Addison-Wesley, 1977. 
APPENDIX A

\section{End User Questionnaire}




\section{Demographic Questionnaire}

For Participant \#:

Date of Trial:

1. Age

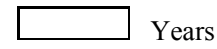

2. Gender

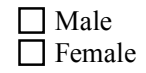

4. Height

\section{Handedness}

$$
\begin{aligned}
& \square \text { Right Handed } \\
& \square \text { Left Handed } \\
& \square \text { Ambidextrous }
\end{aligned}
$$

5. Which scan height did you find most comfortable?
$\square 42$ inches
36 inches
32 inches
26 inches

6. Which scan height did you find most uncomfortable?
$\square 42$ inches
36 inches
$\square 32$ inches
$\square 26$ inches

7. Please rank the following heights in order of preference by writing a 1, 2, 3 or 4 next to each height. 1 is most preferred, 4 is least preferred.

42 inches

36 inches

32 inches

26 inches 
8. When prompted for your thumbs, which method did you prefer?

Both thumbs at the same time

One thumb at a time, LEFT first

$\square$ One thumb at a time, RIGHT first

$\square$ No preference

9. Did you have difficulty repositioning yourself for any of the trials?

$\square$ No

$\square$ Yes, please elaborate on the difficulty you had:

10. Any additional comments on how we can improve the fingerprint capture process?

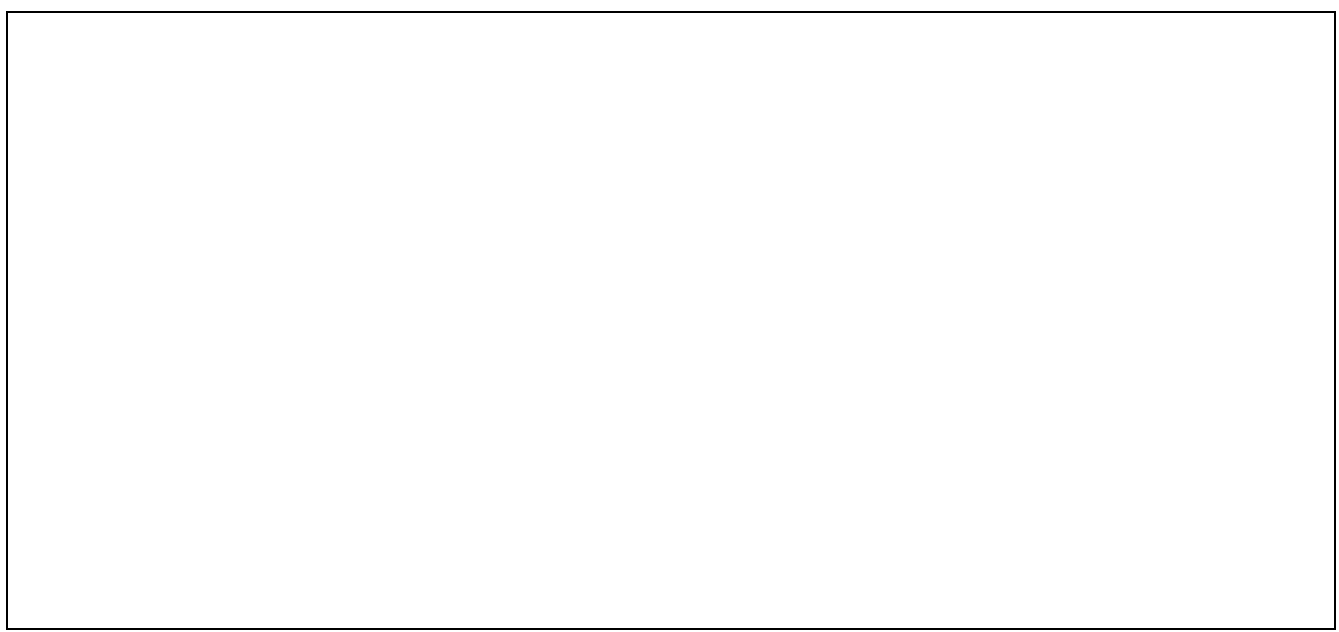




\section{APPENDIX B}

\section{Test Script}


The following test script was verbally presented to each participant in our study by the test system operator. Portions of this script that have been enclosed in brackets ("[" and "]") and are meant as special instructions for the operator. These special instructions guide the operator to tailor instructions for the specific participant or to have the operator perform certain actions.

\section{INTRODUCTION TO PARTICIPANT}

[Welcome the participant]

Thank you for taking the time to participate in our study today.

My name is [name] and we're studying the effectiveness of digital fingerprint scanners at different placements.

One thing we like to stress is that we're testing the placement of the equipment and not your abilities. If you find any part of the test difficult then chances are that others will also. One of the goals of our study is to identify such difficulties so that we work with system designers to make such systems better and easier to use.

During your participation there will be ["others" or "one other person"] observing and I'll introduce you to ["them", "him" or "her"] now.

Today's session will last approximately 15 minutes. If you want to stop at any time just say so.

\section{DESCRIBE EQUIPMENT}

In our study, we'll be using the a digital fingerprint scanner connected to a computer that will be running a program to detect and analyze data from the scanner.

The computer is also responsible for prompting you to take certain actions such as placing your hand on the scanner or removing it.

\section{EXPLANATION OF TASKS}

The study is very simple and consists of three basic tasks.

Task \#1: In this task the computer will instruct you by voice to place either your left or right hand on the scanner. Once instructed to do so, place your left or right four fingers on the scanner and press down until the scanner begins making a continuous beep. Hold your fingers in place until the beep stops.

Your fingers should be close together and as close to the top edge of the finger guard as you can get them comfortably. [demonstrate this action to the subject]. 
Task \#2: In this task the computer will instruct you by voice to place either your left or right thumb on the scanner. Once instructed to do so, place your left or right thumb on the scanner and press down until the scanner begins making a continuous beep. Hold your thumb in place until the beep stops [demonstrate this action to the subject].

Task \#3: In this task the computer will instruct you by voice to place both of your thumbs on the scanner. Once instructed to do so, place your left and right thumb side by side on the scanner and press down until the scanner begins making a continuous beep. Hold your thumbs in place until the beep stops [demonstrate this action to the subject].

These tasks will be randomized so the order will be different.

There will be one repetition of the 5 tasks for each of the four heights that we will be testing the scanner at.

Do you have any questions before we begin?

\section{TRIAL START}

[Start the software and verify Startup Parameters. Click OK to begin.]

We will begin with a test to get you comfortable with the scanner.

Please place your hand on the scanner. Press down and hold it in place until the scanner starts making a beep. Keep your hand in place until the beep stops.

Ready? [once acknowledged, proceed to next step]

[When the software prompts, adjust platform to the lowest height and click OK.]

[Software prompts for right or left hand]

Ok... go ahead and place either hand on the scanner.

[Guide the user as needed to trigger scanner. Once beeping starts ask if the user can hear the beep.]

[*IMPORTANT*: Note which hand the user chose to use. The software will prompt you for this after the very first scan] 
[Follow through additional prompts, repeating the same prompt to the user if he/she did not hear the prompt or did not understand it]

\section{COMPLETION QUESTIONNAIRE}

Thank you for your participation. That concludes the test.

We have a brief questionnaire that we would like you to complete. The information you provide will be for our use only. Your name is not stored with the questionnaire data.

\section{CONCLUSION}

Thanks again for taking the time to participate in our study.

Do you have any comments or questions about today's test session? 


\section{APPENDIX C}

Quality Data 


\begin{tabular}{|c|c|c|c|c|c|c|}
\hline & $26 "$ & $32 "$ & $36 "$ & $42 "$ & Total & \\
\hline \multicolumn{7}{|l|}{ Quality } \\
\hline \multicolumn{7}{|c|}{1} \\
\hline observed & 257.00 & 238.00 & 202.00 & 253.00 & 950.00 & \\
\hline expected & 239.24 & 238.01 & 235.14 & 237.60 & 949.99 & $41.04 \%$ \\
\hline contribution & $1.32 \%$ & $0.00 \%$ & $4.67 \%$ & $1.00 \%$ & & \\
\hline \multicolumn{7}{|c|}{2} \\
\hline observed & 140.00 & 157.00 & 192.00 & 148.00 & 637.00 & \\
\hline expected & 160.42 & 159.59 & 157.67 & 159.32 & 637.00 & $27.52 \%$ \\
\hline contribution & $2.60 \%$ & $4.00 \%$ & $7.48 \%$ & $0.80 \%$ & & \\
\hline \multicolumn{7}{|c|}{3} \\
\hline observed & 114.00 & 110.00 & 88.00 & 105.00 & 417.00 & \\
\hline expected & 105.02 & 104.48 & 103.21 & 104.30 & 417.01 & $18.01 \%$ \\
\hline contribution & $0.77 \%$ & $0.29 \%$ & $2.24 \%$ & $0.00 \%$ & & \\
\hline \multicolumn{7}{|c|}{4} \\
\hline observed & 67.00 & 52.00 & 84.00 & 48.00 & 251.00 & \\
\hline expected & 63.21 & 62.89 & 62.13 & 62.78 & 251.01 & $10.84 \%$ \\
\hline contribution & $0.23 \%$ & $1.88 \%$ & $7.70 \%$ & $3.48 \%$ & & \\
\hline \multicolumn{7}{|c|}{5} \\
\hline observed & 5.00 & 23.00 & 7.00 & 25.00 & 60.00 & \\
\hline expected & 15.11 & 15.03 & 14.85 & 15.01 & 60.00 & $2.59 \%$ \\
\hline contribution & $676.00 \%$ & $422.00 \%$ & $415.00 \%$ & $666.00 \%$ & & \\
\hline $\begin{array}{l}\text { total } \\
\text { observed }\end{array}$ & 583.00 & 580.00 & 573.00 & 579.00 & 2315.00 & \\
\hline & $25.18 \%$ & $25.05 \%$ & $24.75 \%$ & $25.01 \%$ & $100.00 \%$ & \\
\hline
\end{tabular}

Table 7: Finger 1 (Right Thumb Solo) 


\begin{tabular}{|c|c|c|c|c|c|}
\hline & $26 "$ & $32 "$ & $36 "$ & 42" & Total \\
\hline \multicolumn{6}{|l|}{ Quality } \\
\hline \multicolumn{6}{|l|}{1} \\
\hline observed & 264.00 & 261.00 & 261.00 & 269.00 & 1055.00 \\
\hline \multicolumn{6}{|l|}{ expected } \\
\hline contribution & $11.47 \%$ & $11.34 \%$ & $11.34 \%$ & $11.69 \%$ & $45.84 \%$ \\
\hline \multicolumn{6}{|l|}{2} \\
\hline observed & 87.00 & 119.00 & 102.00 & 106.00 & 414.00 \\
\hline \multicolumn{6}{|l|}{ expected } \\
\hline contribution & $3.78 \%$ & $5.17 \%$ & $4.43 \%$ & $4.61 \%$ & $17.99 \%$ \\
\hline \multicolumn{6}{|c|}{3} \\
\hline observed & 126.00 & 108.00 & 119.00 & 114.00 & 467.00 \\
\hline \multicolumn{6}{|l|}{ expected } \\
\hline contribution & $5.48 \%$ & $4.69 \%$ & $5.17 \%$ & $4.95 \%$ & $20.29 \%$ \\
\hline \multicolumn{6}{|l|}{4} \\
\hline observed & 51.00 & 27.00 & 42.00 & 36.00 & 156.00 \\
\hline \multicolumn{6}{|l|}{ expected } \\
\hline contribution & $2.23 \%$ & $1.17 \%$ & $1.83 \%$ & $1.56 \%$ & $6.79 \%$ \\
\hline \multicolumn{6}{|l|}{5} \\
\hline observed & 43.00 & 61.00 & 53.00 & 52.00 & 209.00 \\
\hline \multicolumn{6}{|l|}{ expected } \\
\hline contribution & $1.87 \%$ & $2.65 \%$ & $2.30 \%$ & $2.26 \%$ & $9.08 \%$ \\
\hline $\begin{array}{l}\text { total } \\
\text { observed }\end{array}$ & 571.00 & 576.00 & 577.00 & 577.00 & 2301.00 \\
\hline & $24.82 \%$ & $25.03 \%$ & $25.08 \%$ & $25.08 \%$ & $100.00 \%$ \\
\hline
\end{tabular}

Table 8: Finger 2 (Right Index) 


\begin{tabular}{|c|c|c|c|c|c|c|}
\hline & $26 "$ & $32 "$ & $36 "$ & $42 "$ & Total & \\
\hline \multicolumn{7}{|l|}{ Quality } \\
\hline \multicolumn{7}{|l|}{1} \\
\hline observed & 243.00 & 240.00 & 215.00 & 245.00 & 943.00 & \\
\hline expected & 234.00 & 236.06 & 236.47 & 236.47 & 943.00 & $40.98 \%$ \\
\hline contribution & $3.50 \%$ & $0.07 \%$ & $1.95 \%$ & $0.31 \%$ & & \\
\hline \multicolumn{7}{|l|}{2} \\
\hline observed & 88.00 & 93.00 & 71.00 & 86.00 & 338.00 & \\
\hline expected & 83.88 & 84.61 & 84.76 & 84.76 & 338.01 & $14.69 \%$ \\
\hline contribution & $0.20 \%$ & $0.83 \%$ & $2.23 \%$ & $0.02 \%$ & & \\
\hline \multicolumn{7}{|l|}{3} \\
\hline observed & 94.00 & 97.00 & 135.00 & 118.00 & 444.00 & \\
\hline expected & 110.18 & 111.14 & 111.34 & 111.34 & 444.00 & $19.30 \%$ \\
\hline contribution & $2.38 \%$ & $1.80 \%$ & $5.03 \%$ & $0.40 \%$ & & \\
\hline \multicolumn{7}{|l|}{4} \\
\hline observed & 83.00 & 85.00 & 104.00 & 70.00 & 342.00 & \\
\hline expected & 84.87 & 85.61 & 85.76 & 85.76 & 342.00 & $14.86 \%$ \\
\hline contribution & $0.04 \%$ & $0.00 \%$ & $3.88 \%$ & $2.90 \%$ & & \\
\hline \multicolumn{7}{|l|}{5} \\
\hline observed & 63.00 & 61.00 & 52.00 & 58.00 & 234.00 & \\
\hline expected & 58.07 & 58.58 & 58.68 & 58.68 & 234.01 & $10.17 \%$ \\
\hline contribution & $0.42 \%$ & $0.10 \%$ & $0.76 \%$ & $0.01 \%$ & & \\
\hline $\begin{array}{l}\text { total } \\
\text { observed }\end{array}$ & 571.00 & 576.00 & 577.00 & 577.00 & 2301.00 & \\
\hline & $24.82 \%$ & $25.03 \%$ & $25.08 \%$ & $25.08 \%$ & $100.00 \%$ & \\
\hline
\end{tabular}

Table 9: Finger 3 (Right Middle) 


\begin{tabular}{|c|c|c|c|c|c|c|}
\hline & $26 "$ & $32 "$ & $36 "$ & $42 "$ & Total & \\
\hline \multicolumn{7}{|l|}{ Quality } \\
\hline \multicolumn{7}{|c|}{1} \\
\hline observed & 215 & 179 & 207 & 218 & 819 & \\
\hline expected & 203.24 & 205.02 & 205.37 & 205.37 & 819 & $35.59 \%$ \\
\hline contribution & $0.68 \%$ & $3.30 \%$ & $0.01 \%$ & $0.78 \%$ & & \\
\hline \multicolumn{7}{|c|}{2} \\
\hline observed & 73 & 98 & 50 & 61 & 282 & \\
\hline expected & 69.98 & 70.59 & 70.71 & 70.71 & 281.99 & $12.26 \%$ \\
\hline contribution & $0.13 \%$ & $10.64 \%$ & $6.07 \%$ & $1.33 \%$ & & \\
\hline \multicolumn{7}{|c|}{3} \\
\hline observed & 154 & 165 & 177 & 182 & 678 & \\
\hline expected & 168.25 & 169.72 & 170.02 & 170.02 & 678.01 & $29.47 \%$ \\
\hline contribution & $1.21 \%$ & $0.13 \%$ & $0.29 \%$ & $0.84 \%$ & & \\
\hline \multicolumn{7}{|c|}{4} \\
\hline observed & 55 & 67 & 71 & 57 & 250 & \\
\hline expected & 62.04 & 62.58 & 62.69 & 62.69 & 250 & $10.86 \%$ \\
\hline contribution & $0.80 \%$ & $0.31 \%$ & $1.10 \%$ & $0.52 \%$ & & \\
\hline \multicolumn{7}{|c|}{5} \\
\hline observed & 74 & 67 & 72 & 59 & 272 & \\
\hline expected & 67.5 & 68.09 & 68.21 & 68.21 & 272.01 & $11.82 \%$ \\
\hline contribution & $0.63 \%$ & $0.02 \%$ & $0.21 \%$ & $1.24 \%$ & & \\
\hline $\begin{array}{l}\text { total } \\
\text { observed }\end{array}$ & 571 & 576 & 577 & 577 & 2301 & \\
\hline & $24.82 \%$ & $25.03 \%$ & $25.08 \%$ & $25.08 \%$ & $100.00 \%$ & \\
\hline
\end{tabular}

Table 10: Finger 4 (Right Ring) 


\begin{tabular}{|c|c|c|c|c|c|c|}
\hline & $26 "$ & $32 "$ & $36 "$ & $42 "$ & Total & \\
\hline \multicolumn{7}{|l|}{ Quality } \\
\hline \multicolumn{7}{|c|}{1} \\
\hline observed & 111 & 102 & 109 & 107 & 429 & \\
\hline expected & 106.46 & 107.39 & 107.58 & 107.58 & 429.01 & $18.64 \%$ \\
\hline contribution & $0.19 \%$ & $0.27 \%$ & $0.02 \%$ & $0.00 \%$ & & \\
\hline \multicolumn{7}{|c|}{2} \\
\hline observed & 140 & 120 & 98 & 114 & 472 & \\
\hline expected & 117.13 & 118.15 & 118.36 & 70.71 & 424.35 & $20.51 \%$ \\
\hline contribution & $4.47 \%$ & $0.03 \%$ & $3.50 \%$ & $0.16 \%$ & & \\
\hline \multicolumn{7}{|c|}{3} \\
\hline observed & 164 & 181 & 195 & 157 & 697 & \\
\hline expected & 172.96 & 174.48 & 174.48 & 174.48 & 696.4 & $30.29 \%$ \\
\hline contribution & $0.46 \%$ & $0.24 \%$ & $2.34 \%$ & $1.81 \%$ & & \\
\hline \multicolumn{7}{|c|}{4} \\
\hline observed & 25 & 34 & 21 & 38 & 118 & \\
\hline expected & 29.98 & 29.54 & 29.59 & 29.59 & 118.7 & $5.13 \%$ \\
\hline contribution & $0.63 \%$ & $0.67 \%$ & $2.49 \%$ & $2.39 \%$ & & \\
\hline \multicolumn{7}{|c|}{5} \\
\hline observed & 131 & 139 & 154 & 161 & 585 & \\
\hline expected & 145.17 & 146.44 & 146.69 & 146.69 & 584.99 & $25.42 \%$ \\
\hline contribution & $1.39 \%$ & $0.38 \%$ & $0.36 \%$ & $1.39 \%$ & & \\
\hline $\begin{array}{l}\text { total } \\
\text { observed }\end{array}$ & 571 & 576 & 577 & 577 & 2301 & \\
\hline & $24.82 \%$ & $25.03 \%$ & $25.08 \%$ & $25.08 \%$ & $100.00 \%$ & \\
\hline
\end{tabular}

Table 11: Finger 5 (Right Pinky) 


\begin{tabular}{|c|c|c|c|c|c|c|}
\hline & $26 "$ & $32 "$ & $36 "$ & $42 "$ & Total & \\
\hline \multicolumn{7}{|l|}{ Quality } \\
\hline \multicolumn{7}{|c|}{1} \\
\hline observed & 222 & 203 & 213 & 196 & 834 & \\
\hline expected & 209.31 & 207.87 & 208.95 & 207.87 & 834 & $36.21 \%$ \\
\hline contribution & $0.77 \%$ & $0.11 \%$ & $0.08 \%$ & $0.68 \%$ & & \\
\hline \multicolumn{7}{|c|}{2} \\
\hline observed & 127 & 154 & 135 & 115 & 531 & \\
\hline expected & 133.27 & 132.35 & 133.04 & 132.35 & 531.01 & $23.06 \%$ \\
\hline contribution & $0.29 \%$ & $3.54 \%$ & $0.03 \%$ & $2.27 \%$ & & \\
\hline \multicolumn{7}{|c|}{3} \\
\hline observed & 122 & 109 & 129 & 154 & 514 & \\
\hline expected & 129 & 128.11 & 128.78 & 128.11 & 514 & $22.32 \%$ \\
\hline contribution & $0.38 \%$ & $2.85 \%$ & $0.00 \%$ & $5.23 \%$ & & \\
\hline \multicolumn{7}{|c|}{4} \\
\hline observed & 78 & 70 & 71 & 43 & 262 & \\
\hline expected & 65.76 & 65.3 & 65.64 & 65.3 & 262 & $11.38 \%$ \\
\hline contribution & $2.28 \%$ & $0.34 \%$ & $0.44 \%$ & $7.62 \%$ & & \\
\hline \multicolumn{7}{|c|}{5} \\
\hline observed & 29 & 38 & 29 & 66 & 162 & \\
\hline expected & 40.66 & 40.38 & 40.59 & 40.38 & 162.01 & $7.03 \%$ \\
\hline contribution & $3.34 \%$ & $0.14 \%$ & $3.31 \%$ & $16.26 \%$ & & \\
\hline $\begin{array}{l}\text { total } \\
\text { observed }\end{array}$ & 578 & 574 & 577 & 574 & 2303 & \\
\hline & $25.10 \%$ & $24.92 \%$ & $25.05 \%$ & $24.92 \%$ & $100.00 \%$ & \\
\hline
\end{tabular}

Table 12: Finger 6 (Left Thumb Solo) 


\begin{tabular}{|c|c|c|c|c|c|c|}
\hline & $26 "$ & $32 "$ & $36 "$ & $42 "$ & Total & \\
\hline \multicolumn{7}{|l|}{ Quality } \\
\hline \multicolumn{7}{|c|}{1} \\
\hline observed & 260 & 241 & 256 & 262 & 1019 & \\
\hline expected & & & & & & $44.17 \%$ \\
\hline contribution & $11.27 \%$ & $10.45 \%$ & $11.10 \%$ & $11.36 \%$ & & \\
\hline \multicolumn{7}{|c|}{2} \\
\hline observed & 92 & 132 & 113 & 88 & 425 & \\
\hline expected & & & & & 0 & $18.42 \%$ \\
\hline contribution & $3.99 \%$ & $5.72 \%$ & $4.90 \%$ & $3.81 \%$ & & \\
\hline \multicolumn{7}{|c|}{3} \\
\hline observed & 132 & 124 & 120 & 157 & 533 & \\
\hline expected & & & & & 0 & $23.10 \%$ \\
\hline contribution & $5.72 \%$ & $5.37 \%$ & $5.20 \%$ & $6.81 \%$ & & \\
\hline \multicolumn{7}{|c|}{4} \\
\hline observed & 32 & 26 & 37 & 26 & 121 & \\
\hline expected & & & & & 0 & $5.24 \%$ \\
\hline contribution & $1.39 \%$ & $1.13 \%$ & $1.60 \%$ & $1.13 \%$ & & \\
\hline \multicolumn{7}{|c|}{5} \\
\hline observed & 58 & 58 & 51 & 42 & 209 & \\
\hline expected & & & & & 0 & $9.06 \%$ \\
\hline contribution & $2.51 \%$ & $2.51 \%$ & $2.21 \%$ & $1.82 \%$ & & \\
\hline $\begin{array}{l}\text { total } \\
\text { observed }\end{array}$ & 574 & 581 & 577 & 575 & 2307 & \\
\hline & $24.88 \%$ & $25.18 \%$ & $25.01 \%$ & $24.92 \%$ & $100.00 \%$ & \\
\hline
\end{tabular}

Table 13: Finger 7 (Left Index) 


\begin{tabular}{|c|c|c|c|c|c|c|}
\hline & $26 "$ & $32 "$ & $36 "$ & $42 "$ & Total & \\
\hline \multicolumn{7}{|l|}{ Quality } \\
\hline \multicolumn{7}{|c|}{1} \\
\hline observed & 211 & 219 & 171 & 210 & 811 & \\
\hline expected & 201.78 & 204.24 & 202.84 & 202.13 & 810.99 & $35.15 \%$ \\
\hline contribution & $0.42 \%$ & $1.07 \%$ & $5.00 \%$ & $0.31 \%$ & & \\
\hline \multicolumn{7}{|c|}{2} \\
\hline observed & 63 & 81 & 100 & 75 & 319 & \\
\hline expected & 79.37 & 80.34 & 79.78 & 79.51 & 319 & $13.83 \%$ \\
\hline contribution & $3.38 \%$ & $0.01 \%$ & $5.12 \%$ & $0.26 \%$ & & \\
\hline \multicolumn{7}{|c|}{3} \\
\hline observed & 165 & 132 & 163 & 125 & 585 & \\
\hline expected & 145.55 & 147.33 & 146.31 & 145.81 & 585 & $25.36 \%$ \\
\hline contribution & $2.60 \%$ & $1.59 \%$ & $1.90 \%$ & $2.97 \%$ & & \\
\hline \multicolumn{7}{|c|}{4} \\
\hline observed & 55 & 60 & 66 & 99 & 280 & \\
\hline expected & 69.67 & 70.52 & 70.03 & 69.79 & 280.01 & $12.14 \%$ \\
\hline contribution & $3.09 \%$ & $1.57 \%$ & $0.23 \%$ & $12.23 \%$ & & \\
\hline \multicolumn{7}{|c|}{5} \\
\hline observed & 80 & 89 & 77 & 66 & 312 & \\
\hline expected & 77.63 & 78.57 & 78.03 & 77.76 & 311.99 & $13.52 \%$ \\
\hline contribution & $0.07 \%$ & $1.38 \%$ & $0.01 \%$ & $1.78 \%$ & & \\
\hline $\begin{array}{l}\text { total } \\
\text { observed }\end{array}$ & 574 & 581 & 577 & 575 & 2307 & \\
\hline & $24.88 \%$ & $25.18 \%$ & $25.01 \%$ & $24.92 \%$ & $100.00 \%$ & \\
\hline
\end{tabular}

Table 14: Finger 8 (Left Middle) 


\begin{tabular}{|c|c|c|c|c|c|c|}
\hline & $26 "$ & $32 "$ & $36 "$ & $42 "$ & Total & \\
\hline \multicolumn{7}{|l|}{ Quality } \\
\hline \multicolumn{7}{|c|}{1} \\
\hline observed & 244 & 217 & 233 & 210 & 904 & \\
\hline expected & 224.92 & 227.67 & 226.1 & 225.31 & 904 & $39.19 \%$ \\
\hline contribution & $1.62 \%$ & $0.50 \%$ & $0.21 \%$ & $1.04 \%$ & & \\
\hline \multicolumn{7}{|c|}{2} \\
\hline observed & 48 & 58 & 45 & 54 & 205 & \\
\hline expected & 51.01 & 51.63 & 51.27 & 51.09 & 205 & $8.89 \%$ \\
\hline contribution & $0.18 \%$ & $0.79 \%$ & $0.77 \%$ & $0.17 \%$ & & \\
\hline \multicolumn{7}{|c|}{3} \\
\hline observed & 98 & 137 & 113 & 124 & 472 & \\
\hline expected & 117.44 & 118.87 & 118.05 & 117.64 & 472 & $20.46 \%$ \\
\hline contribution & $3.22 \%$ & $2.77 \%$ & $0.22 \%$ & $0.34 \%$ & & \\
\hline \multicolumn{7}{|c|}{4} \\
\hline observed & 87 & 77 & 83 & 114 & 361 & \\
\hline expected & 89.82 & 90.92 & 90.29 & 89.98 & 361.01 & $15.65 \%$ \\
\hline contribution & $0.09 \%$ & $2.13 \%$ & $0.59 \%$ & $6.41 \%$ & & \\
\hline \multicolumn{7}{|c|}{5} \\
\hline observed & 97 & 92 & 103 & 73 & 365 & \\
\hline expected & 90.81 & 91.92 & 91.29 & 90.97 & 364.99 & $15.82 \%$ \\
\hline contribution & $0.42 \%$ & $0.00 \%$ & $1.50 \%$ & $3.55 \%$ & & \\
\hline $\begin{array}{l}\text { total } \\
\text { observed }\end{array}$ & 574 & 581 & 577 & 575 & 2307 & \\
\hline & $24.88 \%$ & $25.18 \%$ & $25.01 \%$ & $24.92 \%$ & $100.00 \%$ & \\
\hline
\end{tabular}

Table 15: Finger 9 (Left Ring) 


\begin{tabular}{|c|c|c|c|c|c|c|}
\hline & $26 "$ & $32 "$ & $36 "$ & $42 "$ & Total & \\
\hline \multicolumn{7}{|l|}{ Quality } \\
\hline \multicolumn{7}{|c|}{1} \\
\hline observed & 90 & 89 & 67 & 76 & 322 & \\
\hline expected & 80.12 & 81.09 & 80.53 & 80.26 & 322 & $13.96 \%$ \\
\hline contribution & $1.22 \%$ & $0.77 \%$ & $2.27 \%$ & $0.23 \%$ & & \\
\hline \multicolumn{7}{|c|}{2} \\
\hline observed & 115 & 88 & 109 & 96 & 408 & \\
\hline expected & 101.51 & 102.75 & 102.04 & 101.69 & 407.99 & $17.69 \%$ \\
\hline contribution & $1.79 \%$ & $2.12 \%$ & $0.47 \%$ & $0.32 \%$ & & \\
\hline \multicolumn{7}{|c|}{3} \\
\hline observed & 154 & 204 & 205 & 213 & 776 & \\
\hline expected & 193.07 & 195.43 & 194.08 & 193.41 & 775.99 & $33.64 \%$ \\
\hline contribution & $7.91 \%$ & $0.38 \%$ & $0.61 \%$ & $1.98 \%$ & & \\
\hline \multicolumn{7}{|c|}{4} \\
\hline observed & 33 & 35 & 41 & 26 & 135 & \\
\hline expected & 33.59 & 34 & 33.76 & 33.65 & 135 & $5.85 \%$ \\
\hline contribution & $0.01 \%$ & $0.03 \%$ & $1.55 \%$ & $1.74 \%$ & & \\
\hline \multicolumn{7}{|c|}{5} \\
\hline observed & 182 & 165 & 155 & 164 & 666 & \\
\hline expected & 165.71 & 167.73 & 166.57 & 165.99 & 666 & $28.87 \%$ \\
\hline contribution & $1.60 \%$ & $0.04 \%$ & $0.80 \%$ & $0.02 \%$ & & \\
\hline $\begin{array}{l}\text { total } \\
\text { observed }\end{array}$ & 574 & 581 & 577 & 575 & 2307 & \\
\hline & $24.88 \%$ & $25.18 \%$ & $25.01 \%$ & $24.92 \%$ & $100.00 \%$ & \\
\hline
\end{tabular}

Table 16: Finger 10 (Left Pinky) 


\begin{tabular}{|c|c|c|c|c|c|c|}
\hline & $26 "$ & $32 "$ & $36 "$ & $42 "$ & Total & \\
\hline \multicolumn{7}{|l|}{ Quality } \\
\hline \multicolumn{7}{|c|}{1} \\
\hline observed & 241 & 234 & 225 & 166 & 866 & \\
\hline expected & 217.44 & 215.56 & 216.31 & 216.69 & 866 & $37.42 \%$ \\
\hline contribution & $2.55 \%$ & $1.58 \%$ & $0.35 \%$ & $11.86 \%$ & & \\
\hline \multicolumn{7}{|c|}{2} \\
\hline observed & 65 & 45 & 59 & 61 & 230 & \\
\hline expected & 57.75 & 57.25 & 57.45 & 57.55 & 230 & $9.94 \%$ \\
\hline contribution & $0.91 \%$ & $2.62 \%$ & $0.04 \%$ & $0.21 \%$ & & \\
\hline \multicolumn{7}{|c|}{3} \\
\hline observed & 89 & 103 & 77 & 83 & 352 & \\
\hline expected & 88.38 & 87.62 & 87.92 & 88.08 & 352 & $15.21 \%$ \\
\hline contribution & $0.00 \%$ & $2.70 \%$ & $1.36 \%$ & $0.29 \%$ & & \\
\hline \multicolumn{7}{|c|}{4} \\
\hline observed & 70 & 54 & 65 & 56 & 245 & \\
\hline expected & 61.51 & 60.99 & 61.2 & 61.3 & 245 & $10.59 \%$ \\
\hline contribution & $1.17 \%$ & $0.80 \%$ & $0.24 \%$ & $0.46 \%$ & & \\
\hline \multicolumn{7}{|c|}{5} \\
\hline observed & 116 & 140 & 152 & 213 & 621 & \\
\hline expected & 155.92 & 154.58 & 155.12 & 155.38 & 621 & $26.84 \%$ \\
\hline contribution & $10.22 \%$ & $1.38 \%$ & $0.06 \%$ & $21.36 \%$ & & \\
\hline $\begin{array}{l}\text { total } \\
\text { observed }\end{array}$ & 581 & 576 & 578 & 579 & 2314 & \\
\hline & $25.11 \%$ & $24.89 \%$ & $24.98 \%$ & $25.02 \%$ & $100.00 \%$ & \\
\hline
\end{tabular}

Table 17: Finger 11 (Right Thumb Both) 


\begin{tabular}{|c|c|c|c|c|c|c|}
\hline & $26 "$ & $32 "$ & $36 "$ & $42 "$ & Total & \\
\hline \multicolumn{7}{|l|}{ Quality } \\
\hline \multicolumn{7}{|c|}{1} \\
\hline observed & 261 & 277 & 203 & 184 & 925 & \\
\hline expected & 232.25 & 230.25 & 231.05 & 231.45 & 925 & $39.97 \%$ \\
\hline contribution & $3.56 \%$ & $9.49 \%$ & $3.41 \%$ & $9.73 \%$ & & \\
\hline \multicolumn{7}{|c|}{2} \\
\hline observed & 74 & 56 & 83 & 76 & 289 & \\
\hline expected & 72.56 & 71.94 & 72.19 & 72.31 & 289 & $12.49 \%$ \\
\hline contribution & $0.03 \%$ & $3.53 \%$ & $1.62 \%$ & $0.19 \%$ & & \\
\hline \multicolumn{7}{|c|}{3} \\
\hline observed & 56 & 52 & 77 & 67 & 252 & \\
\hline expected & 63.27 & 62.73 & 62.95 & 63.05 & 252 & $10.89 \%$ \\
\hline contribution & $0.84 \%$ & $1.83 \%$ & $3.14 \%$ & $0.25 \%$ & & \\
\hline \multicolumn{7}{|c|}{4} \\
\hline observed & 57 & 44 & 51 & 42 & 194 & \\
\hline expected & 48.71 & 48.29 & 48.46 & 48.54 & 194 & $8.38 \%$ \\
\hline contribution & $1.41 \%$ & $0.38 \%$ & $0.13 \%$ & $0.88 \%$ & & \\
\hline \multicolumn{7}{|c|}{5} \\
\hline observed & 133 & 147 & 164 & 210 & 654 & \\
\hline expected & 164.21 & 162.79 & 163.36 & 163.64 & 654 & $28.26 \%$ \\
\hline contribution & $5.93 \%$ & $1.53 \%$ & $0.00 \%$ & $13.10 \%$ & & \\
\hline $\begin{array}{l}\text { total } \\
\text { observed }\end{array}$ & 581 & 576 & 578 & 579 & 2314 & \\
\hline & $25.11 \%$ & $24.89 \%$ & $24.98 \%$ & $25.02 \%$ & $100.00 \%$ & \\
\hline
\end{tabular}

Table 18: Finger 12 (Left Thumb Both) 


\begin{tabular}{|c|c|c|c|c|}
\hline $\begin{array}{c}\text { Left Hand } \\
\text { Finger Number }\end{array}$ & $26 "$ & $32 \%$ & $36 ”$ & $42 \%$ \\
\hline 6 & $41.9 \%$ & $43.4 \%$ & $43.0 \%$ & $35.2 \%$ \\
\hline 12 & $25.0 \%$ & $24.7 \%$ & $12.3 \%$ & $1.4 \%$ \\
\hline 7 & $45.7 \%$ & $49.7 \%$ & $48.7 \%$ & $49.0 \%$ \\
\hline 8 & $24.2 \%$ & $26.0 \%$ & $22.2 \%$ & $20.9 \%$ \\
\hline 9 & $18.8 \%$ & $18.2 \%$ & $16.0 \%$ & $13.4 \%$ \\
\hline 10 & $-1.7 \%$ & $-4.0 \%$ & $-3.5 \%$ & $-3.1 \%$ \\
\hline
\end{tabular}

Table 19: Percentage difference of NFIQ 1 and 2 to 4 and 5

\begin{tabular}{|c|l|l|l|l|}
\hline $\begin{array}{c}\text { Right Hand } \\
\text { Finger Number }\end{array}$ & \multicolumn{1}{|c|}{$26 "$} & \multicolumn{1}{|c|}{$32 \%$} & \multicolumn{1}{|c|}{$36 \%$} & $42 \%$ \\
\hline 1 & $55.8 \%$ & $55.2 \%$ & $52.9 \%$ & $56.7 \%$ \\
\hline 11 & $20.7 \%$ & $14.8 \%$ & $11.6 \%$ & $-7.3 \%$ \\
\hline $2^{*} 6$ & & & & \\
\hline 3 & $32.4 \%$ & $32.5 \%$ & $22.5 \%$ & $35.2 \%$ \\
\hline 4 & $27.9 \%$ & $24.8 \%$ & $19.8 \%$ & $28.3 \%$ \\
\hline 5 & $16.6 \%$ & $8.5 \%$ & $5.6 \%$ & $3.8 \%$ \\
\hline
\end{tabular}

Table 20: Percentage difference of NFIQ 1 and 2 to 4 and 5

${ }^{6}$ No reliable difference was calculated for this finger at all heights. 